\title{
Physiological and transcriptomic analyses reveal the roles of secondary metabolism in the adaptive responses of Stylosanthes to manganese toxicity
}

Yidan $\mathrm{Jia}^{1,2+}$, Xinyong $\mathrm{Li}^{1+}$, Qin Liu ${ }^{3}$, Xuan $\mathrm{Hu}^{1}$, Jifu Li ${ }^{1,2}$, Rongshu Dong ${ }^{1}$, Pandao Liu${ }^{1}$, Guodao Liu ${ }^{1}$, Lijuan Luo ${ }^{2^{*}}$ and Zhijian Chen ${ }^{1,2^{*}}$ (D)

\begin{abstract}
Background: As a heavy metal, manganese (Mn) can be toxic to plants. Stylo (Stylosanthes) is an important tropical legume that exhibits tolerance to high levels of Mn. However, little is known about the adaptive responses of stylo to Mn toxicity. Thus, this study integrated both physiological and transcriptomic analyses of stylo subjected to $\mathrm{Mn}$ toxicity.

Results: Results showed that excess Mn treatments increased malondialdehyde (MDA) levels in leaves of stylo, resulting in the reduction of leaf chlorophyll concentrations and plant dry weight. In contrast, the activities of enzymes, such as peroxidase (POD), phenylalanine ammonia-lyase (PAL) and polyphenol oxidase (PPO), were significantly increased in stylo leaves upon treatment with increasing Mn levels, particularly Mn levels greater than $400 \mu \mathrm{M}$. Transcriptome analysis revealed 2471 up-regulated and 1623 down-regulated genes in stylo leaves subjected to Mn toxicity. Among them, a set of excess Mn up-regulated genes, such as genes encoding PAL, cinnamyl-alcohol dehydrogenases (CADs), chalcone isomerase (CHI), chalcone synthase (CHS) and flavonol synthase $(F L S)$, were enriched in secondary metabolic processes based on gene ontology $(\mathrm{GO})$ analysis. Numerous genes associated with transcription factors (TFs), such as genes belonging to the $\mathrm{C} 2 \mathrm{H} 2$ zinc finger transcription factor, WRKY and MYB families, were also regulated by Mn in stylo leaves. Furthermore, the $\mathrm{C} 2 \mathrm{H} 2$ and MYB transcription factors were predicted to be involved in the transcriptional regulation of genes that participate in secondary metabolism in stylo during $\mathrm{Mn}$ exposure. Interestingly, the activation of secondary metabolism-related genes probably resulted in increased levels of secondary metabolites, including total phenols, flavonoids, tannins and anthocyanidins.

\footnotetext{
* Correspondence: luoljd@126.com; jchen@scau.edu.cn

†Yidan Jia and Xinyong Li contributed equally to this work.

${ }^{2}$ Hainan Key Laboratory for Sustainable Utilization of Tropical Bioresources, College of Tropical Crops, Hainan University, Haikou 570110, China

'Institute of Tropical Crop Genetic Resources, Chinese Academy of Tropical Agricultural Sciences, Haikou 571101, China

Full list of author information is available at the end of the article
}

(c) The Author(s). 2020 Open Access This article is licensed under a Creative Commons Attribution 4.0 International License, which permits use, sharing, adaptation, distribution and reproduction in any medium or format, as long as you give appropriate credit to the original author(s) and the source, provide a link to the Creative Commons licence, and indicate if changes were made. The images or other third party material in this article are included in the article's Creative Commons licence, unless indicated otherwise in a credit line to the material. If material is not included in the article's Creative Commons licence and your intended use is not permitted by statutory regulation or exceeds the permitted use, you will need to obtain permission directly from the copyright holder. To view a copy of this licence, visit http://creativecommons.org/licenses/by/4.0/ The Creative Commons Public Domain Dedication waiver (http://creativecommons.org/publicdomain/zero/1.0/) applies to the data made available in this article, unless otherwise stated in a credit line to the data. 
(Continued from previous page)

Conclusions: Taken together, this study reveals the roles of secondary metabolism in the adaptive responses of stylo to Mn toxicity, which is probably regulated by specific transcription factors.

Keywords: Stylosanthes, Manganese toxicity, Oxidative stress, Secondary metabolism, Transcription factor, Transcriptomics, Heavy metal

\section{Background}

Of the mineral nutrients, manganese $(\mathrm{Mn})$ is essential for plant growth and participates in a series of metabolic processes, such as photosynthesis, respiration, secondary metabolism and protein biosynthesis [1]. Mn acts as a cofactor of many enzymes, such as superoxide dismutase (SOD) and enzymes involved in the tricarboxylic acid cycle. Mn also plays roles in flavonoid and lignin biosynthesis [2]. As a trace element, $\mathrm{Mn}$ is only required in small amounts of 20-40 mg Mn per kilogram dry weight for most plants [3]. However, $\mathrm{Mn}$ is also considered to be a heavy metal that can cause phytotoxicity when it reaches the level of $150 \mathrm{mg}$ per kilogram dry weight in plants [1].

In soils, available $\mathrm{Mn}$ levels fluctuate from 450 to $4000 \mathrm{mg}$ per kilogram, and Mn solubility is mainly dependent on $\mathrm{pH}$ values and redox conditions $[4,5]$. Hence, excess Mn toxicity generally occurs in acid soils due to the accumulation of bioactive divalent Mn (II) [5, 6]. Consequently, soil amelioration, such as lime application, is typically conducted to alleviate Mn toxicity by decreasing Mn availability, but this application is costly from both economic and environmental aspects [7]. For these reasons, breeding crop varieties with superior $\mathrm{Mn}$ tolerance represents a sustainable alternative agronomical strategy, but this strategy requires better understanding of how plants respond to $\mathrm{Mn}$ toxicity. Although morphological changes in plants grown under the condition of Mn toxicity vary among plant species, the appearances of $\mathrm{Mn}$ toxicity reported in most plants generally include leaf chlorosis, brown spots, crinkled leaves and brown roots, and ultimately plant growth inhibition [8,9]. Adverse impacts caused by Mn toxicity have also been documented in plant cells at physiological levels, such as triggering oxidative stress, causing lipid peroxidation, inhibiting enzyme activity, impairing chlorophyll biosynthesis and photosynthesis and disturbing the uptake and translocation of other mineral elements $[1,9]$.

To counteract Mn toxicity, plants are equipped with sophisticated adaptive strategies to detoxify $\mathrm{Mn}$, such as modified Mn translocation and distribution, sequestration of Mn into subcellular compartment, antioxidant system activation, and adjusted root organic acid exudation [9]. Cumulative results show that reactive oxygen species (ROS) scavenging systems involving antioxidant enzymes, including peroxidase (POD) and ascorbate peroxidase (APX), are regulated by the plant's response to Mn toxicity, thereby alleviating excess Mn-induced oxidative stress [10, 11]. Furthermore, secondary metabolic processes and metabolites, such as phenolics, flavonoids and phenylalanine, are regulated by Mn stress in plants $[2,12,13]$, suggesting the potential roles of secondary metabolism in the adaptation of plants to Mn toxicity. To date, some key genes have been characterized that participate in Mn uptake, translocation and distribution and help plants address environmental Mn stress [14, 15]. For example, as one of the natural resistanceassociated macrophage protein (Nramp) members, OsNramp3 in rice (Oryza sativa) is a plasma membrane $\mathrm{Mn}$ transporter and responsible for $\mathrm{Mn}$ distribution from young leaves and panicles to old tissues, thereby protecting plants from Mn toxicity [16]. Metal tolerance proteins (MTPs) belonging to the cation diffusion facilitator (CDF) family, such as ShMTP1 from the Caribbean stylo (Stylosanthes hamata) [17], OsMTP8.1 and OsMTP8.2 from rice [18, 19], AtMTP8 from Arabidopsis [20], CsMTP8 from cucumber (Cucumis sativus) [21] and CasMTP8 from the tea plant (Camellia sinensis) [22], are involved in sequestering $\mathrm{Mn}$ into the vacuole for detoxification. Although the roles of the above genes have been functionally characterized, the transcriptome profiles of Mn-responsive genes in plants have not been fully elucidated. Studying the responses of plants to varying Mn concentrations is useful to determine how plants cope with Mn toxicity.

Stylo (Stylosanthes spp.) is a dominant tropical legume that is widely grown in tropical areas worldwide [23, 24]. Superior Mn tolerance is observed in the stylo compared to other legumes [25]. Recently, it has been documented that high Mn adaptability in stylo may be achieved by its fine regulation of proteins involved in specific pathways, such as defense response, photosynthesis and metabolism [11]. Furthermore, important roles of organic acids, such as malate, in stylo adaptation to Mn toxicity have been reported; a malate dehydrogenase (SgMDH1) enzyme that is up-regulated in response to $\mathrm{Mn}$ catalyzes malate synthesis and contributes to Mn detoxification [26]. Although stylo has considerable potential for $\mathrm{Mn}$ tolerance, the effects of excess $\mathrm{Mn}$ toxicity on profile 
alterations in the gene expression of stylo have not been reported, and the molecular responses of stylo to $\mathrm{Mn}$ stress remain largely unknown. Previous studies have paved the way for the current study dissecting the molecular responses of stylo to $\mathrm{Mn}$ toxicity. Accordingly, in this study, the effects of various Mn concentrations on the physiological changes in stylo were first investigated. Transcriptomic analysis of Mn-responsive genes in stylo leaves was further performed using an RNA-seq approach. The results of this study provide a platform to understand the adaptive responses of stylo to Mn toxicity and the genes involved.

\section{Results}

\section{Effects of excess Mn stress on stylo growth}

Thirty-day-old stylo plants were subjected to Mn treatments ranging from 5 to $800 \mu \mathrm{M} \mathrm{MnSO}_{4}$ for $10 \mathrm{~d}$. Leaf chlorosis, a symptom of Mn toxicity, was observed in stylo leaves treated with greater than $200 \mu \mathrm{M}$ Mn, especially 400 and $800 \mu \mathrm{M}$ Mn (Fig. 1a). $\mathrm{O}_{2}^{-}$levels were observed in leaves based on nitroblue tetrazolium chloride (NBT) staining (Fig. 1b). $\mathrm{O}_{2}{ }^{-}$accumulation was mainly observed in leaves treated with excess $\mathrm{Mn}$ compared with the control $(5 \mu \mathrm{M})$, and the most intense blue color was observed in leaves treated with $800 \mu \mathrm{M}$ Mn (Fig. 1b). Consistent with this finding, increases in malondialdehyde (MDA) levels were observed in stylo leaves subjected to high Mn stress. MDA concentrations in leaves exposed to 400 and $800 \mu \mathrm{M}$ Mn treatments were 55.4 and $103.9 \%$ greater, respectively, compared with control conditions (Fig. 1c). Furthermore, the relative electrolyte leakage of stylo leaves was significantly increased under Mn treatments exceeding $200 \mu \mathrm{M}$ (Additional file 1: Fig. S1). In contrast, leaf chlorophyll concentrations were decreased by $35.0-79.1 \%$ upon treatment with 200 to $800 \mu \mathrm{M}$ Mn compared with the control (Fig. 1d). Similarly, the maximum quantum yield of photosystem II $(F \mathrm{~V} / F \mathrm{~m})$ significantly declined in stylo under $\mathrm{Mn}$ treatments from 200 to $800 \mu \mathrm{M}$ Mn compared with the controls (Additional file 1: Fig. S1), suggesting that photosynthesis was inhibited by Mn toxicity.

Stylo shoot and root growth were inhibited by $\mathrm{Mn}$ concentrations greater than $200 \mu \mathrm{M}$. The shoot dry weight was reduced by $29.4-50.0 \%$ with 200 to $800 \mu \mathrm{M}$ Mn treatments, whereas root dry weight decreased by $18.3-40.2 \%$ with 200 to $800 \mu \mathrm{M}$ Mn treatment compared with their respective controls (Fig. 2a, b). Additionally, stylo plant height decreased at Mn levels greater than

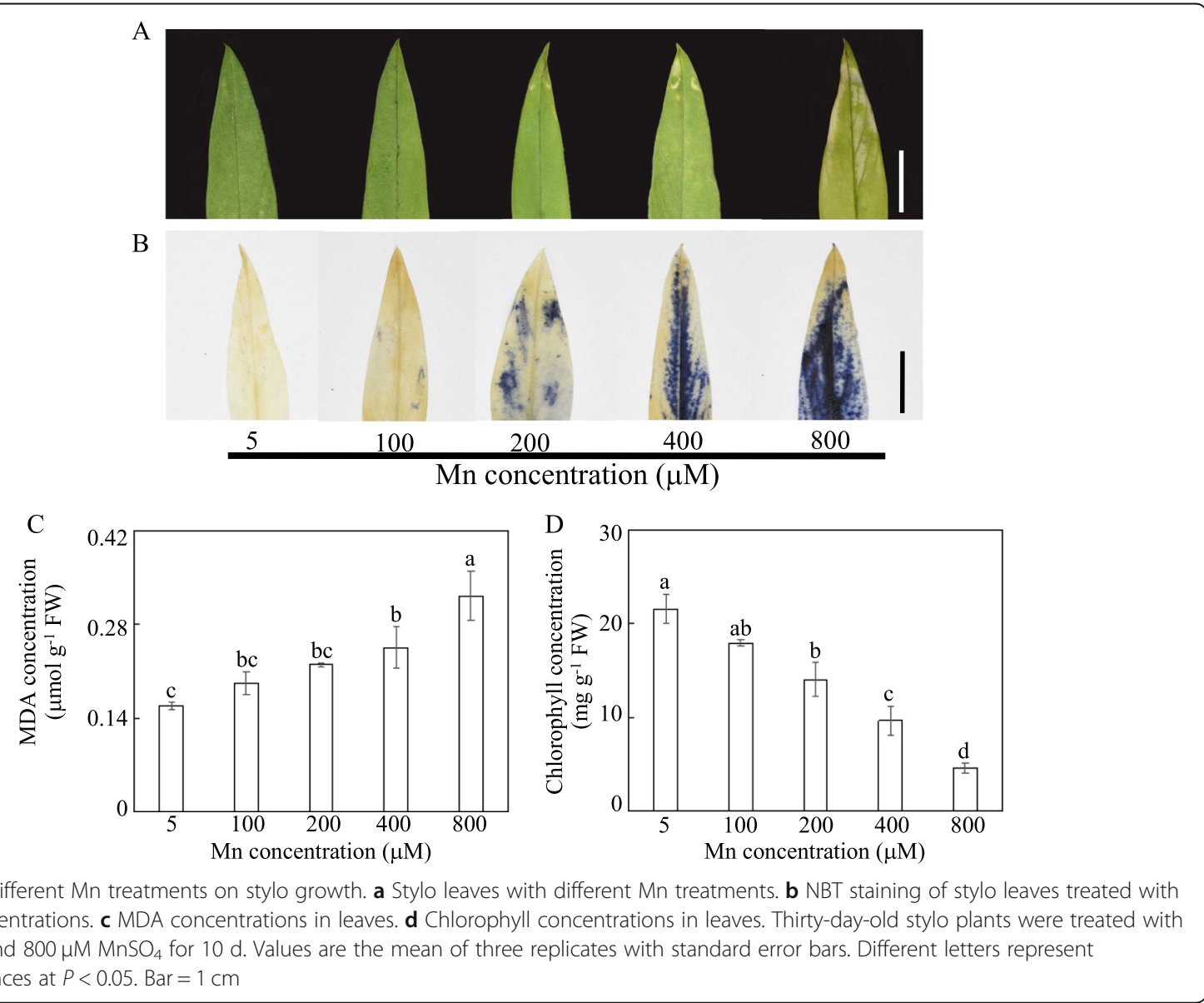




\section{A}
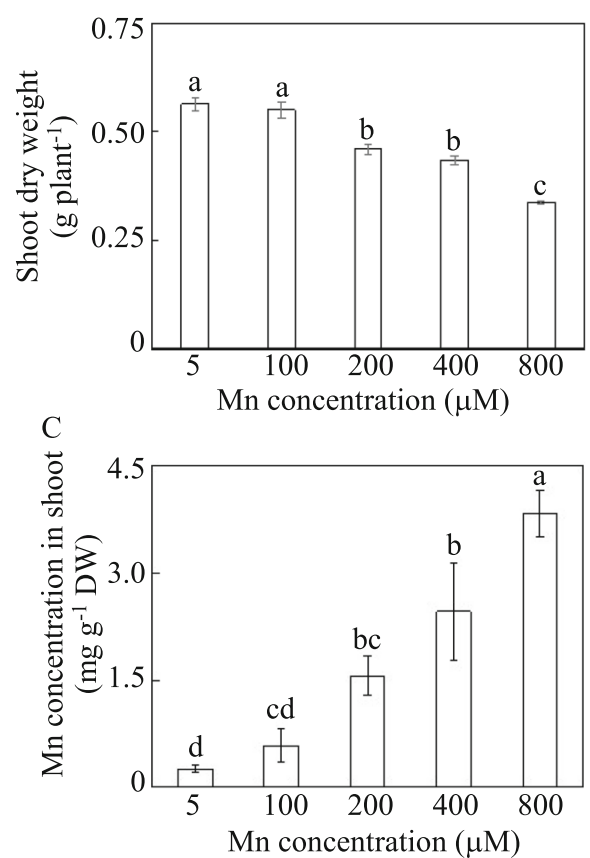

B

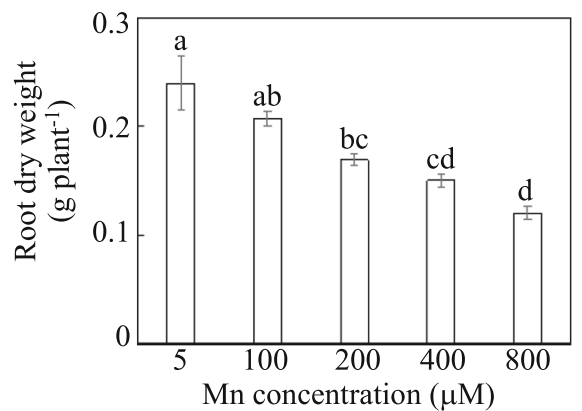

$\mathrm{D}$

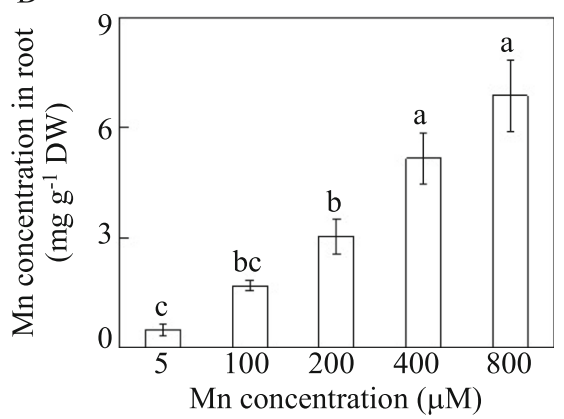

Fig. 2 Plant dry weight and Mn concentrations in stylo under different Mn treatments. a Shoot dry weight. b Root dry weight. c Shoot Mn concentrations. $\mathbf{d}$ Root Mn concentrations. Thirty-day-old stylo plants were treated with 5 to $800 \mu \mathrm{M} \mathrm{MnSO} 4$ for 10 d. Values are the mean of three replicates with standard error bars. Different letters represent significant differences at $P<0.05$

$400 \mu \mathrm{M}$ compared with the controls (Additional file 1: Fig. S1). Increases in Mn concentrations were found in both stylo shoots and roots under Mn stress. Mn concentrations in shoots and roots were increased by more than 2.2-fold and 3.5-fold with more than $100 \mu \mathrm{M} \mathrm{Mn}$ compared with their respective controls (Fig. 2c, d).

\section{Enzyme activity response to excess $\mathrm{Mn}$}

Activities of peroxidase (POD), ascorbate peroxidase (APX), polyphenol oxidase (PPO) and phenylalanine ammonia-lyase (PAL) were analyzed in stylo leaves exposed to Mn treatments. The results showed that the tested enzymes were differentially regulated by $\mathrm{Mn}$ (Fig. 3). Compared to their respective controls, POD and APX activities increased as Mn treatments increased from 200 to $800 \mu \mathrm{M}$, peaking at $400 \mu \mathrm{M}$ Mn (Fig. 3a, b). POD and APX activities increased by 2.9-fold and 0.41fold with $400 \mu \mathrm{M}$ Mn treatment compared to their respective controls (Fig. 3a, b).

In addition, increases in PPO and PAL activities were also found in stylo leaves under Mn stress, especially 400 and $800 \mu \mathrm{M}$ Mn treatments (Fig. 3c, d). PPO and PAL activities in stylo leaves treated with $400 \mu \mathrm{M} \mathrm{Mn}$ were 54.7 and $35.8 \%$ increased compared with their controls (Fig. 3c, d).

\section{Transcriptome analysis of stylo leaves responding to $\mathrm{Mn}$ toxicity}

In this study, comparative transcriptomic analysis in stylo leaves subjected to 5 and $400 \mu \mathrm{M}$ Mn treatments was performed. Approximately 48.4 and 51.6 million clean reads were obtained from the libraries of the stylo leaves treated under control $\mathrm{Mn}(5 \mu \mathrm{M})$ and toxic $\mathrm{Mn}$ $(400 \mu \mathrm{M})$ conditions (Additional file 2: Table S1), respectively. As the genome sequence for stylo is not available, a de novo assembly approach was employed. De novo assembly of the reads produced 234,557 transcripts corresponding to 102,872 unigenes from all samples (Additional file 2: Table S1). The mean lengths of transcripts and unigenes were 1132 and $869 \mathrm{bp}$, respectively (Additional file 2: Table S1).

Differentially expressed genes (DEGs) in stylo leaves exposed to $\mathrm{Mn}$ treatments were identified based on $\mid \log 2$ (fold change) $\mid \geq 1$ and $q<0.05$. A total of 4094 DEGs were identified via comparison of the two $\mathrm{Mn}$ treatments (Additional file 3: Table S2). Among these genes, 2471 genes were up-regulated, while 1623 genes were down-regulated by $\mathrm{Mn}$ toxicity (Additional file 3: Table S2). Gene ontology (GO) analysis showed that the identified DEGs can be classified into 21 biological processes (BP), 17 cellular components $(\mathrm{CC})$, and 11 molecular function (MF) terms (Fig. 4). The main 

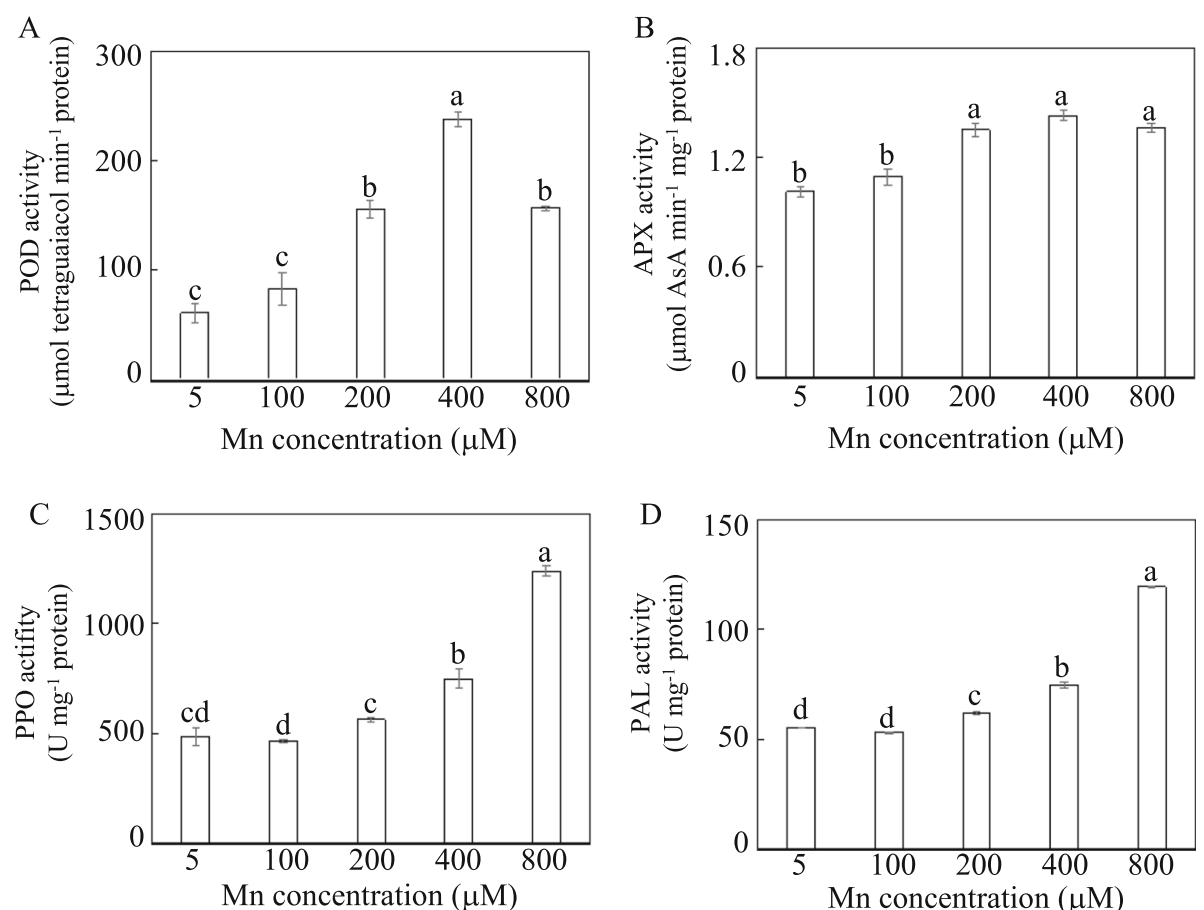

Fig. 3 Determination of enzyme activities. a POD activity. b APX activity. c PPO activity. d PAL activity. Thirty-day-old stylo plants were treated with 5 to $800 \mu \mathrm{M} \mathrm{MnSO}_{4}$ for $10 \mathrm{~d}$. Values are the mean of three replicates with standard error bars. Different letters represent significant differences at $P<0.05$

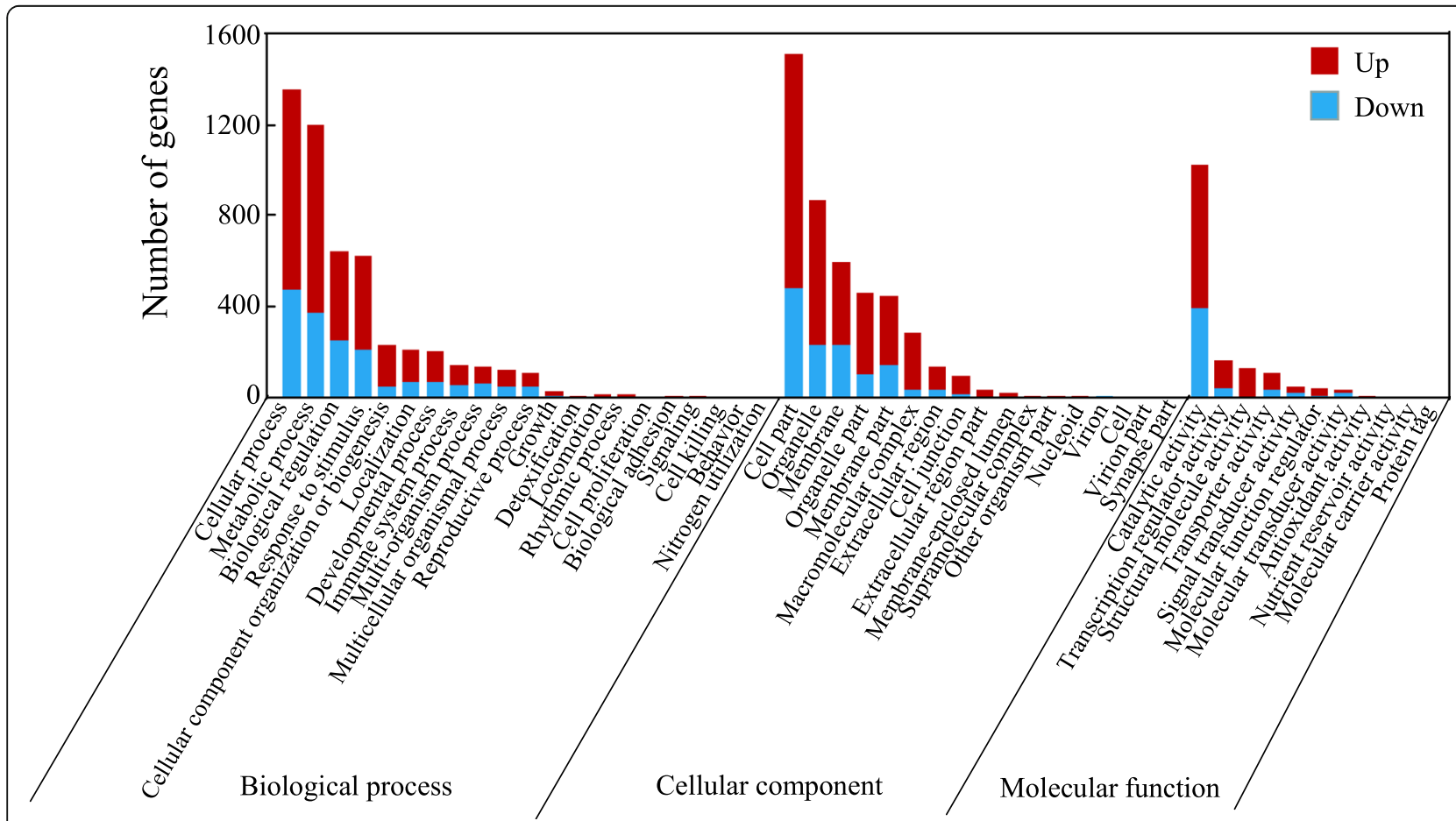

Fig. $4 \mathrm{GO}$ analysis of DEGs in stylo. The up or down-regulated genes were classified into biological process, cellular component and molecular function. $X$ - and Y-axis indicate GO terms and the number of DEGs, respectively 
categories in BP included cellular process, metabolic process, biological regulation and response to stimulus terms. The dominant categories in CC included cell part, organelle and membrane. Prominent MF categories included catalytic activity, transcription regulator activity and structural molecule activity (Fig. 4). Furthermore, DEGs were mainly involved in the following pathways based on Kyoto Encyclopedia of Genes and Genomes (KEGG) enrichment analysis: ribosome, plant hormone signal transduction, plant-pathogen interaction, glutathione metabolism, phenylpropanoid biosynthesis, DNA replication, sesquiterpenoid and triterpenoid biosynthesis, and isoflavonoid biosynthesis (Fig. 5).

Secondary metabolic pathways in response to Mn toxicity According to GO analysis, a total of 1201 unigenes were predicted to be involved in metabolic processes in the BP categories, including 824 up-regulated unigenes and 377 down-regulated unigenes (Fig. 4). Among these DEGs, a set of 94 genes were enriched in seven secondary metabolic pathways (Additional file 4: Table S3). The top Mn-responsive genes belonged to phenylpropanoid metabolic process, flavonoid metabolic process, isoflavonoid metabolic process and lignin metabolic process (Fig. 6). Interestingly, a large number of genes in the above pathways were enhanced by Mn toxicity. For example, genes encoding PAL, $\beta$-glucosidases (GLUs), cinnamoyl-CoA reductase (CCR), cinnamyl-alcohol dehydrogenases (CADs), feruloyl$\mathrm{CoA}$ 6-hydroxylases (F6Hs) and caffeic acid 3-Omethyltransferases (COMTs), were up-regulated in the phenylpropanoid biosynthesis pathway (Fig. 7). In addition, the transcript of genes encoding chalcone isomerases (CHIs), one homolog of chalcone synthase (CHS) and flavonol synthases (FLSs) associated with the flavonoid biosynthesis pathway, isoflavone 7-O-methyltransferase (I7OMT), 2- hydroxyisoflavanone dehydratase (HIDH), isoflavone 2hydroxylase (I2H) and vestitone reductases (VRs) related to the isoflavonoid biosynthesis process was enhanced in stylo under Mn toxicity (Fig. 7). Furthermore, transcripts of $P A L$ and a set of homologs of I7OMT and gene encoding anthranilate $\mathrm{N}$-methyltransferase-like in the above pathways were increased by more than 8-fold under Mn stress (Additional file 4: Table S3).

\section{Transcription factors involved in stylo responses to $\mathrm{Mn}$ toxicity}

A total of 123 DEGs were enriched in transcription factors (TFs) (Additional file 5: Tables S4). Among them, the largest group of TFs belonged to the AP2 family with 23 up-regulated and 1 down-regulated genes. Other DEGs encoding TFs included 22 MYBs, 16 ZFs, 15 HLHs, 11 NAMs, 9 WRKYs, 5 HSFs, 5 TCPs, 3 GRASs, 2 $E I N s$, and one of each of the following genes: NF-X1, $K$ box, QLQ, PHD, SRF-TF, Homeobox, E2F-TDP, CCT, B3, $H B$ and $S B P$ (Fig. 8). Among them, 11 genes were significantly increased by greater than 8 -fold under $\mathrm{Mn}$ toxicity: DREB group protein, protein PPLZ02, dehydration-responsive element-binding protein 1E-like, ethyleneresponsive transcription factor 4 and TINY transcription factor belonging to the AP2 family; myb-related protein $\mathrm{Zm} 1$ belonging to the MYB family; zinc finger of $\mathrm{C} 2 \mathrm{H} 2$ type belonging to the ZF family; transcription factor bHLH18-like belonging to the HLH family; hypothetical protein LR48 belonging to the WRKY family; heat shock factor protein HSF30-like belonging to the HSF family; hypothetical protein GLYMA belonging to the NF-X1 family, and MADS-box transcription factor 1-like isoform $X 1$ belonging to the K-box family (Additional file 5: Table S4).

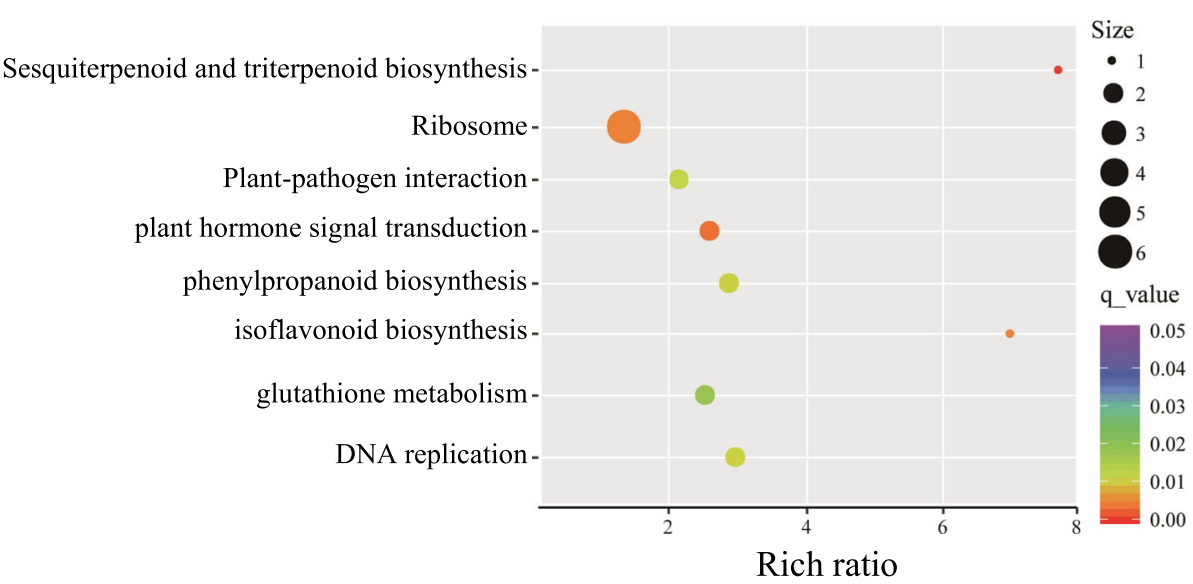

Fig. 5 KEGG enrichment analysis of the DEGs. R package ggplot2 was used to data visualization. Rich ratio is the number of significant genes divided by background genes of corresponding pathway term. The size of the dot represents the number of DEGs and the color indicates $q-$ value (the corrected $p$-value) of the pathway term 


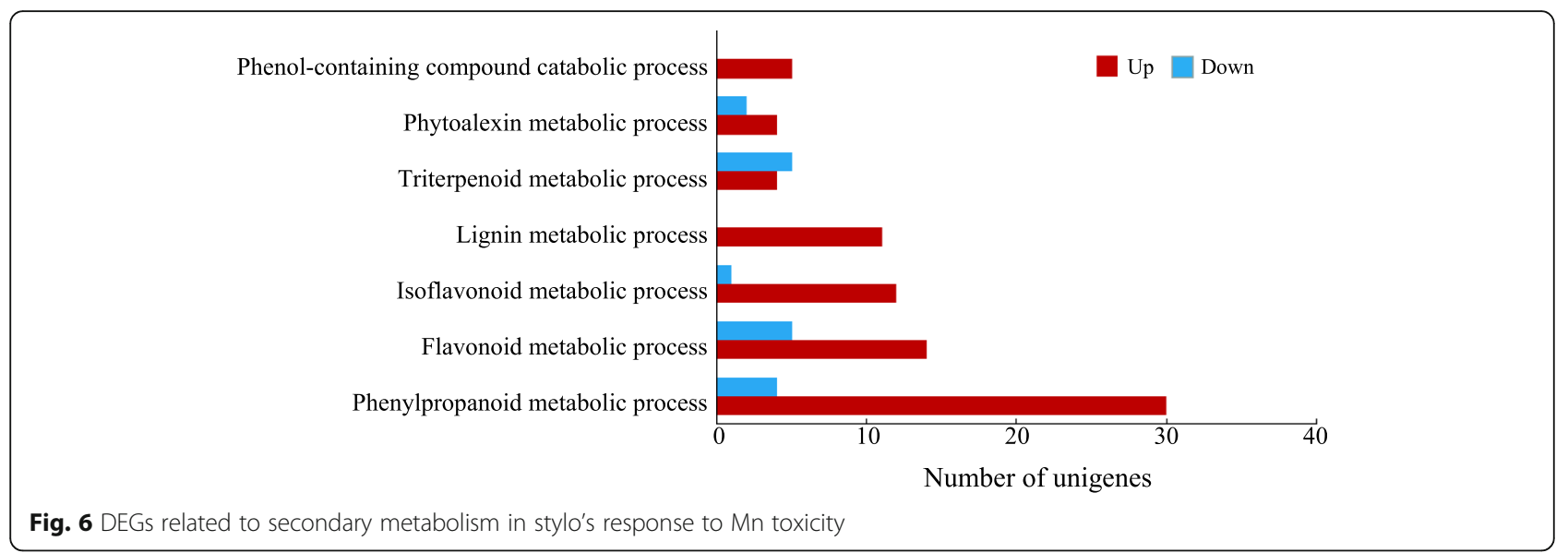

\section{Protein-protein interaction network analysis}

To explore the candidate TFs involved in the transcriptional regulation of genes associated with secondary metabolism in stylo during Mn exposure, the protein-protein interaction networks of DEGs related to secondary metabolic pathways and TFs were further constructed. The interaction networks contained 305 edges with 72 nodes (Fig. 9). Among them, two genes CAD1/2 (TRINITY DN21432_c0_g1 and TRINITY_DN45912_c0_g3) were regulated by six TFs, all of which belonged to $\mathrm{C} 2 \mathrm{H} 2$ zinc finger transcription factors (TRINITY_DN12526_c0_g1, TRINITY_DN42276_c1_g1, RINITY_DN54332_c0_g1, TRINITY_DN13820_c0_g1, TRINITY_DN46140_c3_g3 and TRINITY_DN47158_c1_g1) (Fig. 9). Furthermore,
$H I D H$ (TRINITY_DN56723_c0_g1) can be regulated by the $M Y B$ gene (TRINITY_DN42931_c2_g2) and a NAClike transcription factor (TRINITY_DN45594_c4_g1) (Fig. 9). In addition, genes encoding anthocyanidin reductase (TRINITY_DN52696_c0_g1) and hypothetical protein (TRINITY_DN45901_c1_g1) were the targets of the $M Y B$ gene (TRINITY_DN42931_c2_g2) (Fig. 9). These results suggest that the candidate TFs highlighted above may be involved in the regulation of secondary metabolismrelated genes in the response of stylo to Mn toxicity.

\section{Validation of RNA-seq data using qRT-PCR}

To confirm the RNA-seq data, 15 DEGs involved in secondary metabolism and TFs were further selected for

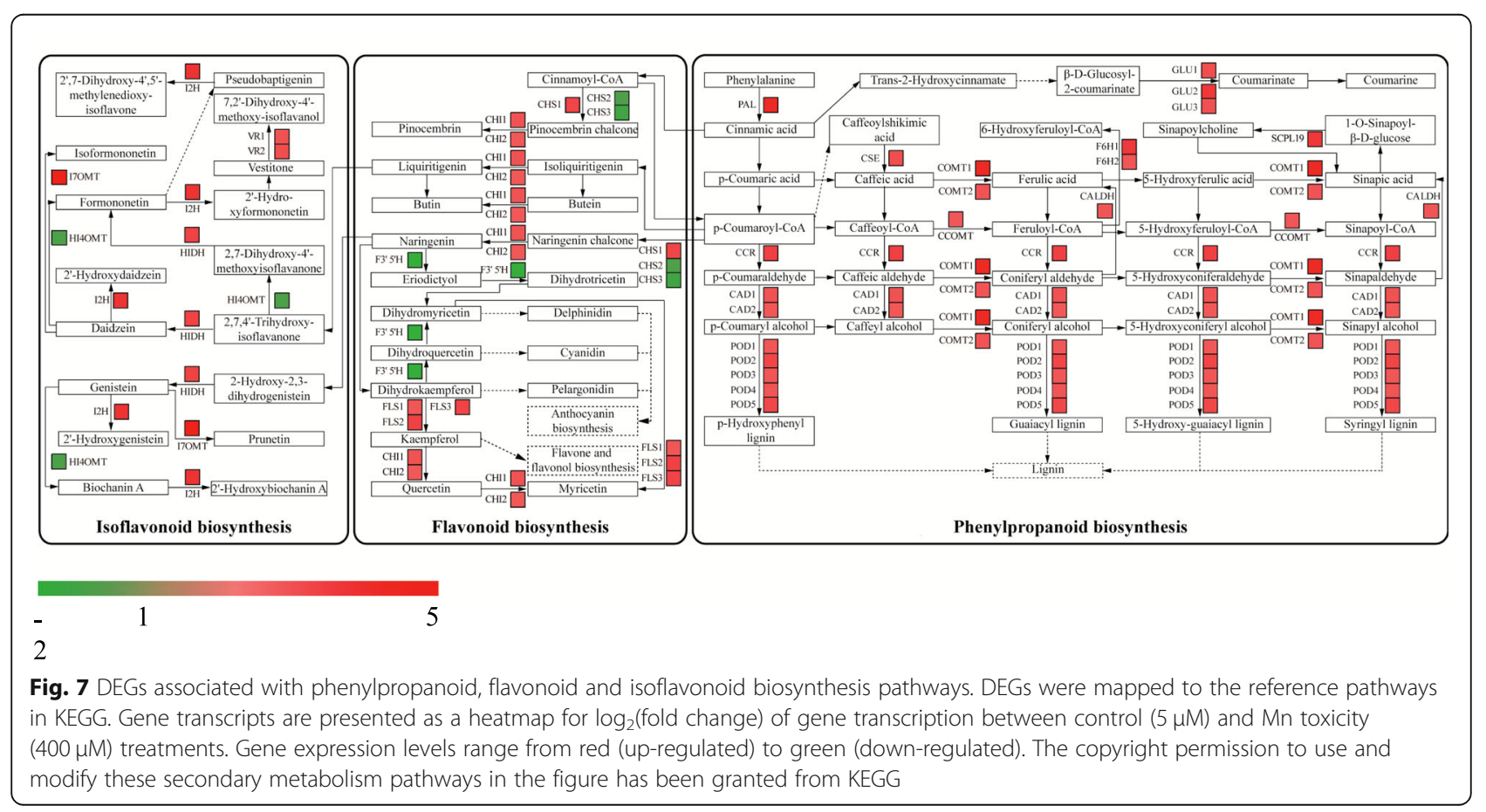




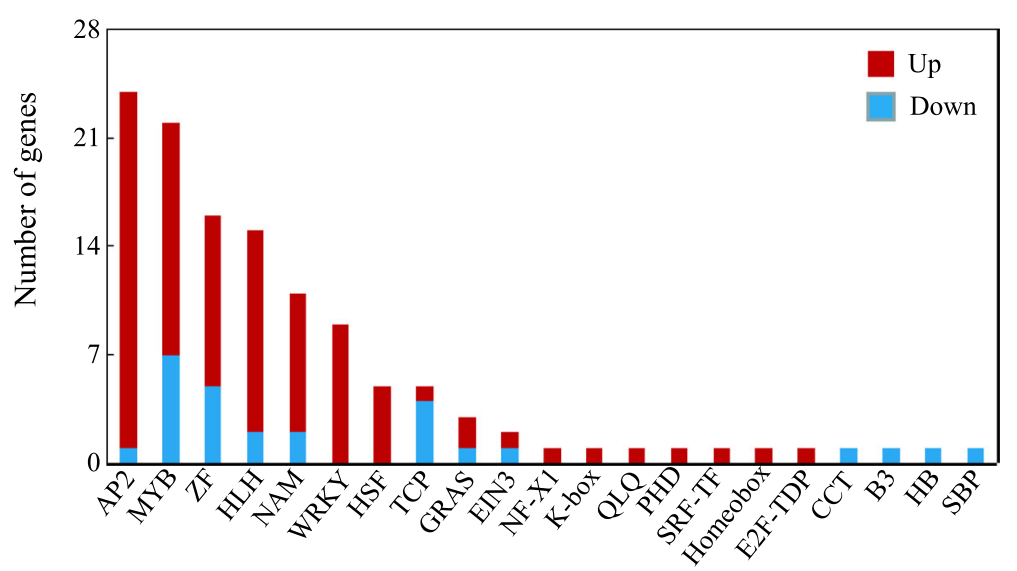

Fig. 8 DEGs associated with transcription factors in stylo leaves. $X$ - and $Y$-axis indicate the abbreviation and the number of TFs, respectively

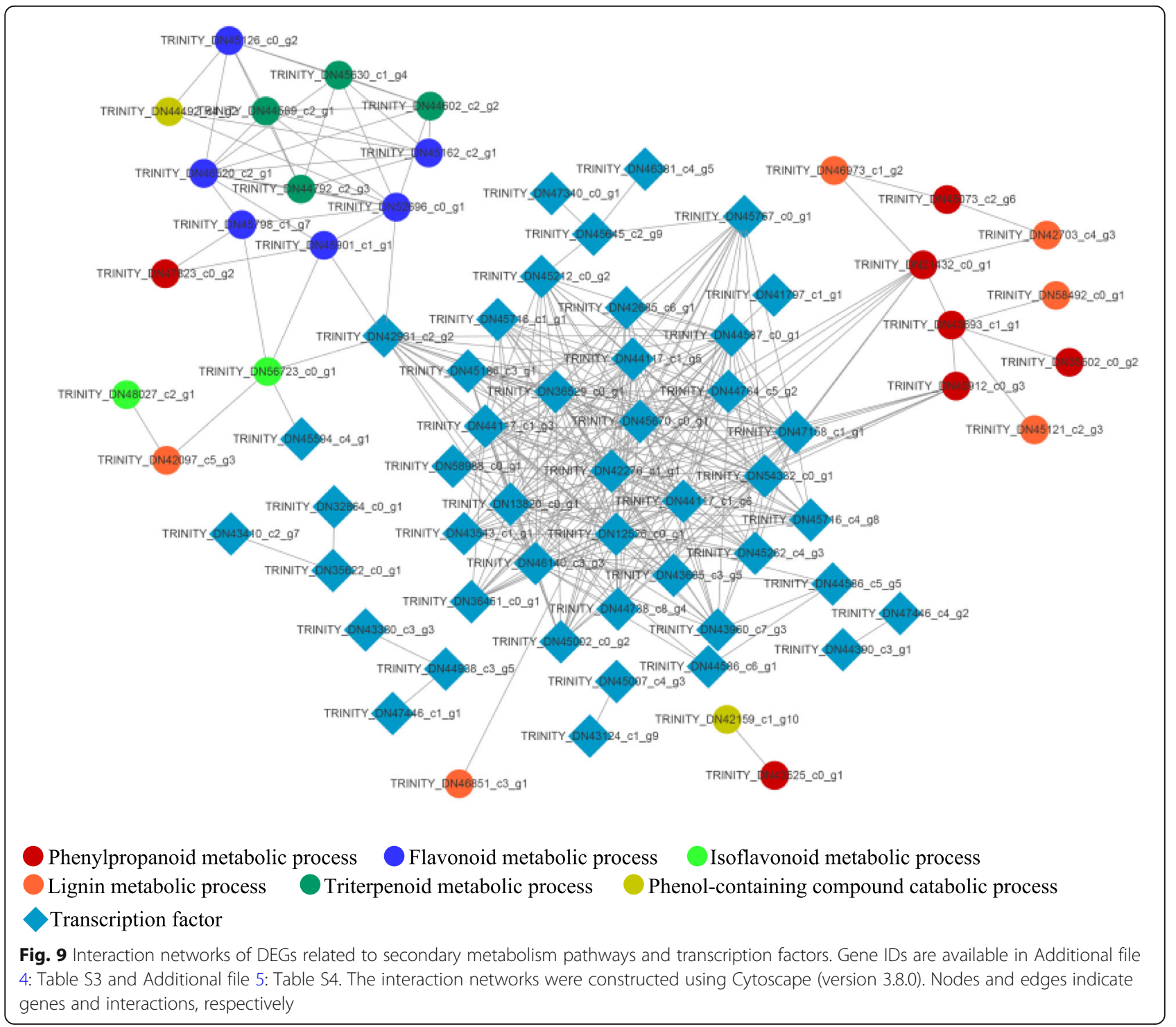


qRT-PCR analysis (Fig. 10). These DEGs included 10 up-regulated and five down-regulated genes. The results showed a significant correlation $\left(\mathrm{R}^{2}=0.887, p<0.01\right)$ between the RNA-seq data and qRT-PCR results (Fig. 10), suggesting the reliability of the RNA-seq data.

\section{Changes in secondary metabolite levels under Mn stress}

Subsequently, the concentrations of four secondary metabolites, including total phenols, flavonoids, tannins and anthocyanidins, in stylo leaves treated with various $\mathrm{Mn}$ concentrations were further detected. Compared to their respective controls, the levels of total phenols, tannins and anthocyanidins in stylo leaves increased with 400 and $800 \mu \mathrm{M}$ Mn treatments, while the concentrations of flavonoids increased with $\mathrm{Mn}$ treatments increasing from 200 to $800 \mu \mathrm{M}$, peaking at $800 \mu \mathrm{M}$ (Fig. 11). Furthermore, the concentrations of total phenols, flavonoids, tannins and anthocyanidins in stylo leaves subjected to $400 \mu \mathrm{M}$ Mn treatment were increased 1.1-, 1.6-, 2.1- and 7.4-fold, respectively, compared with their controls (Fig. 11). These results suggest that secondary metabolism may play a key role in stylo's response to Mn toxicity.

\section{Discussion}

Although $\mathrm{Mn}$ is a trace element required for plant growth, Mn phytotoxicity generally occurs, especially in acid soil regions worldwide $[8,9]$. Mn toxicity not only causes adverse impacts in plant cells but also threatens human health $[27,28]$. In recent decades, genome-wide identification of metal responsive genes through transcriptomic techniques has been conducted to investigate the molecular mechanisms of plant adaptation to heavy metal stresses [29-31]. However, the transcriptome profiles of plants in response to Mn toxicity have not been well documented. In this study, the molecular responses of stylo to Mn toxicity were investigated through integration of physiological and transcriptomic analyses, providing potential $\mathrm{Mn}$-tolerant strategies in plants for further study.

\section{Response of stylo to $\mathrm{Mn}$ toxicity}

Stylo growth was inhibited by high Mn stress, as reflected by the inhibition of leaf chlorophyll concentrations and plant dry weight, especially under 400 and $800 \mu \mathrm{M} \mathrm{Mn}$ treatments (Figs. 1 and 2). Similarly, decreases in plant growth are also observed in ryegrass (Lolium perenne), white clover (Trifolium repens) and polish wheat (Triticum polonicum) under Mn toxicity $[32,33]$. Stylo growth inhibition might be due to the overproduction of ROS, as indicated by the accumulation of $\mathrm{O}_{2}{ }^{-}$and MDA (Fig. 1), which was supported by the results obtained from a previous study in stylo [11]. A considerable increase in oxidative stress is also found in polish wheat leaves under Mn toxicity, inhibiting shoot and root growth [33].

RNA-seq analysis was further conducted to identify DEGs in stylo's response to Mn toxicity. The identified DEGs can be classified into numerous pathways (Fig. 4), suggesting various adjustments in stylo's response to $\mathrm{Mn}$ toxicity. Among them, a large number of excess $\mathrm{Mn}$ regulated genes were categorized as defense response genes, including homologous genes encoding antioxidant enzymes, such as POD and APX (Additional file 6: Table S5). This finding is consistent with a previous study demonstrating that homologous genes encoding antioxidant enzymes are up-regulated in stylo and citrus (Citrus grandis) in response to $\mathrm{Mn}$ toxicity [11, 34]. Furthermore, excess Mn up-regulation of $P O D$ and $A P X$ transcripts may result in increasing POD and APX activities in stylo leaves subjected to excess Mn toxicity (Fig. 3 and Additional file 6: Table S5), suggesting that these antioxidant enzymes may participate in ROS scavenging in stylo. In addition, 8 out of 10 genes encoding homologs to glutathione S-transferase (GST) were upregulated by Mn toxicity (Additional file 6: Table S5). As a cellular detoxification enzyme, GST protects plants from oxidative damage $[35,36]$. Homologous genes of GST play protective roles in plants against different stresses. For instance, the expression of OsGSTLs is enhanced by arsenic (As) stress in rice, and overexpression of OsGSTL2 increases tolerance to As, cadmium $(\mathrm{Cd})$ and chromium $(\mathrm{Cr})$ stresses in transgenic Arabidopsis [35].

Moreover, other DEGs belonging to defense response related proteins, such as pathogenesis-related proteins (PRs), disease-resistance proteins (DRPs), heat shock proteins (HSPs), chitinases, beta-1,3-glucanases (GLUs) and late embryogenesis abundant proteins (LEAs), were also identified in this study (Additional file 6: Table S5). Homologues of these genes are regulated by $\mathrm{Mn}$ or other metal stresses [11, 29, 30, 37, 38], suggesting that overlap between metal stress responses may be conserved in stylo and other plants.

\section{DEGs involved in secondary metabolism}

A group of DEGs involved in plant secondary metabolism, such as phenylpropanoid, flavonoid and isoflavonoid biosynthesis processes, were identified in this study (Figs. 6 and 7), suggesting that secondary metabolism is regulated by $\mathrm{Mn}$ toxicity. In the phenylpropanoid pathway, for example, the expression of $P A L$ was upregulated by $\mathrm{Mn}$ stress in the transcriptome data (Fig. 7). $P A L$ is a key gene that catalyzes phenylalanine to form cinnamic acid in the phenylpropanoid pathway, which plays important roles in plant stress tolerance [39, 40]. Heavy metal treatments, such as lead $(\mathrm{Pb})$, increase the transcript level of $P A L$ or its enzyme activity in 


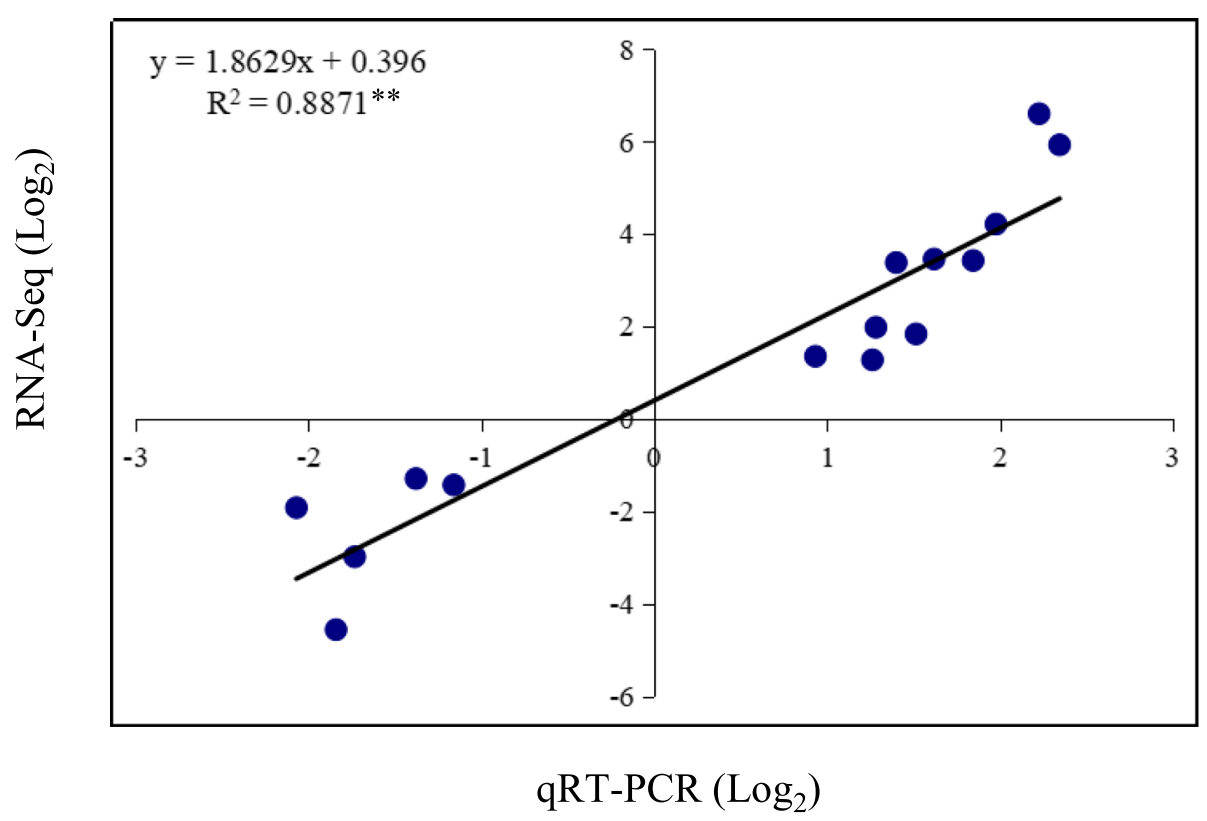

Fig. 10 Correlation analysis of gene expression between transcriptome data and qRT-PCR results. Ten up-regulated and five down-regulated DEGs were selected for qRT-PCR analysis. Transcriptome data were plotted against data from qRT-PCR. Data are presented on a $\log _{2} \mathrm{scale}$
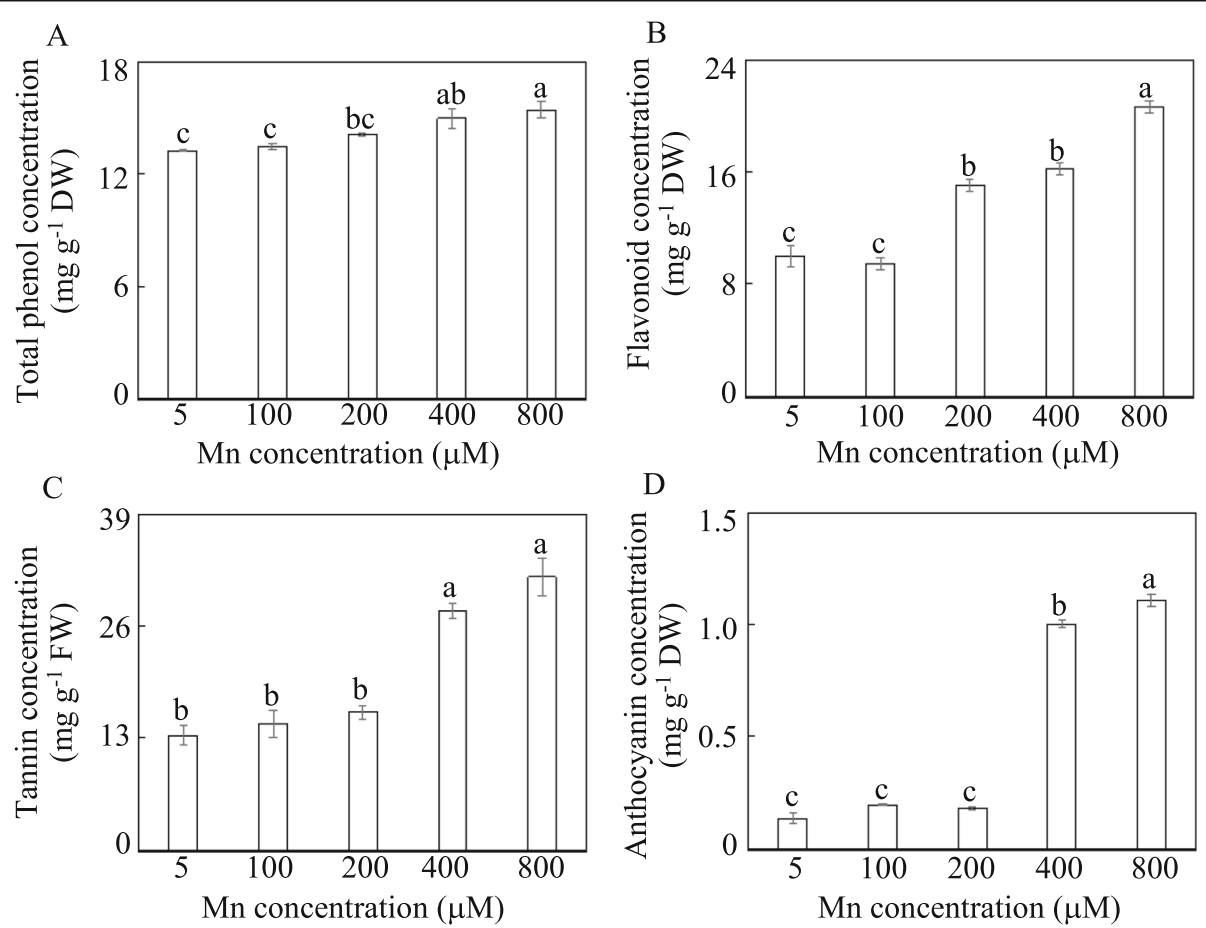

Fig. 11 Concentrations of secondary metabolites in stylo leaves subjected to different Mn treatments. a Total phenols. b Flavonoids. c Tannins. d Anthocyanins. Thirty-day-old stylo plants were treated with 5 to $800 \mu \mathrm{M} \mathrm{MnSO}_{4}$ for $10 \mathrm{~d}$. Values are the mean of three replicates with standard error bars. Different letters represent significant differences at $P<0.05$ 
soybean (Glycine max), lupine (Lupinus luteus) and tomato (Lycopersicon esculentum) [41, 42]. Accordingly, increased $P A L$ transcript levels may enhance its enzyme activity in stylo's response to Mn toxicity (Figs. 3 and 7). Furthermore, some genes encoding proteins involved in different steps in the phenylpropanoid biosynthesis pathway, such as CCR, CADs, COMTs, F6Hs and PODs, were all up-regulated in stylo subjected to Mn toxicity (Fig. 7). Similar results are found in proteomic analysis of stylo, in which a group of proteins associated with the phenylpropanoid metabolic pathway are up-regulated under excess $\mathrm{Mn}$ stress [11]. Therefore, these results strongly suggest that the phenylpropanoid biosynthesis process is activated in stylo to counteract Mn stress.

The flavonoid biosynthesis process is performed by a set of key genes encoding CHSs, CHIs, FLSs and F3,5H, which were found to be regulated by Mn toxicity in this study (Fig. 7). CHS, CHI and FLS transcripts are regulated by abiotic stresses, such as UV light, wounding and heavy metal toxicity [42-44]. For example, CHS is a key gene involved in regulating flavonoid biosynthesis; $\mathrm{CHS}$ expression is enhanced in Pb-exposed tomato [42]. Similarly, CHI expression is increased in pea roots (Pisum sativum) under Cd stress [45]. In addition, ZmFLS1 in maize is induced by UV-B radiation, and high expression levels of ZmFLS1 protect plants from UV-B stress [43]. In addition, DEGs belonging to isoflavonoid metabolism related proteins, such as HIDH, I2H, I7OMT and VRs, were also regulated by $\mathrm{Mn}$ stress (Fig. 7). Isoflavonoids are a predominant subclass of flavonoid metabolites that play critical roles in plant defense $[46,47]$.

As important osmotic regulators and ROS scavengers in plant stress tolerance, secondary metabolites are regulated by Mn stress in many plants, such as phenylalanine in Populus cathayana [13], lignin and flavonoid in rice [2], and phenol and callose in cowpea (Vigna unguiculata) [12]. Similarly, in this study, significant increases in secondary metabolites, including total phenols, flavonoids, tannins and anthocyanins, were observed in stylo leaves exposed to 400 and $800 \mu \mathrm{M}$ Mn (Fig. 11). The accumulation of secondary metabolites might be attributed to the regulation of various genes, such as $P A L, C C R$, $C A D, C H S, C H I, F L S$ and HIDH (Fig. 7). Cumulative results suggest that increasing gene expression can cause the accumulation of secondary metabolites. For example, increases in $C H S$ and $P A L$ transcripts are closely related to the increased levels of phenols, flavonoids and anthocyanins in tomato under Pb stress [42]. Furthermore, exogenous expression of ZmFLS1 from maize increases anthocyanin accumulation in an Arabidopsis fls1 mutant [43]. Although the exact roles of the candidate DEGs described above warrant further research, the results presented in this study strongly suggest that adjustment of secondary metabolism and corresponding gene expression might be important for stylo adaptation to Mn toxicity.

\section{DEGs related to transcription factors}

In this study, the identification of 123 transcription factors suggested complex regulation in stylo's response to Mn toxicity (Fig. 8 and Additional file 5: Table S4). Among those identified transcription factors, seven DEGs belonging to the $\mathrm{C} 2 \mathrm{H} 2$ zinc finger transcription factor family were up-regulated by Mn toxicity in stylo (Additional file 5: Table S4). $\mathrm{C} 2 \mathrm{H} 2$ transcription factors are implicated in low $\mathrm{pH}$-stress and aluminum (Al) toxicity tolerance in many plants, such as AtSTOP1/2 in Arabidopsis, VuSTOP1 in rice bean (Vigna umbellata) and GmSTOP1s in soybean [48-51]. For example, GmSTOP1-1/1-3 expression is enhanced by $\mathrm{Al}$ toxicity in soybean roots; complementation analyses of GmSTOP1s in an Arabidopsis Atstop1 mutant suggest that GmSTOP1s play critical roles in Al tolerance [51]. Furthermore, it has been demonstrated that $\mathrm{C} 2 \mathrm{H} 2$ transcription factors function in $\mathrm{Al}$ detoxification mainly through activation of $\mathrm{Al}$-tolerant genes, such as gene encoding glutamate dehydrogenase 1 (GDH1), pectin methylesterase inhibitor (PMI), malic enzyme (ME), aluminum-activated malate transporter (ALMT), multidrug and toxic compound exclusion protein (MATE) and tonoplast dicarboxylate transporter (TDT) [48, 49, 51]; these homologous genes were also up-regulated by Mn toxicity in stylo (Additional file 3: Table S2), suggesting that the functions of $\mathrm{C} 2 \mathrm{H} 2$ transcription factors may be conserved in $\mathrm{Mn}$ detoxification through regulation of downstream critical Mn-resistant genes. Interestingly, two DEGs, $C A D 1 / 2$, which belong to the phenylpropanoid biosynthesis pathway, were predicted to be regulated by six $\mathrm{C} 2 \mathrm{H} 2$ transcription factors (Fig. 9), suggesting that these $\mathrm{C} 2 \mathrm{H} 2$ transcription factors may also play transcriptional regulatory roles in secondary metabolism in stylo during Mn exposure, which deserves further study.

Moreover, nine transcription factor genes belonging to the WRKY family were up-regulated by Mn toxicity in stylo (Additional file 5: Table S4). Although the function of WRKY transcription factor remains largely unknown in stylo's response to Mn toxicity, WRKY46 in Arabidopsis a negative regulator of ALMT1; disruption of WRKY46 results in increased malate exudation, conferring $\mathrm{Al}$ tolerance [52]. However, WRKY46 expression in Arabidopsis is suppressed by Al toxicity [52], but WRKY gene transcripts in stylo were enhanced by Mn stress in this study (Additional file 5: Table S4), suggesting that there are other regulatory networks that are mediated by WRKY-mediated gene expression in stylo during $\mathrm{Mn}$ toxicity. 
Additionally, 22 transcription factors belonging to the MYB family were identified in this study (Additional file 5: Table S4). Cumulative studies have demonstrated that MYB family transcription factors participate in the response to environmental stresses in plants [53]. For example, MYB49 expression in Arabidopsis is induced by Cd treatment; overexpression of MYB49 in Arabidopsis results in a significant increase in $\mathrm{Cd}$ accumulation, inhibiting primary root growth [54]. Furthermore, MYB49 interacts with the transcription factors bHLH38 and bHLH101, leading to the activation of IRON-REGULATED TRANSPORTER1 and mediating Cd uptake [54]. In addition, OsARM1, which encodes the R2R3 MYB transcription factor, is induced by As treatment in rice. OsARM1 knockout improves tolerance to As stress in rice through regulation of As transporters, thereby mediating As uptake and translocation [55]. Furthermore, in this study, the MYB transcription factor is probably involved in the regulation of secondary metabolic pathways by mediating the transcripts of genes belonging to $\mathrm{HIDH}$, anthocyanidin reductase and hypothetical protein (Fig. 9). Thus, future efforts are required to investigate the functions of these transcription factors in stylo subjected to Mn toxicity.

\section{DEGs related to transporters}

Different kinds of DEGs belonging to transporters possibly involved in $\mathrm{Mn}$ translocation, distribution and sequestration were identified in this study (Additional file 7: Table S6). Among them, a set of genes encoding homologs to ATP-binding cassette (ABC) transporters were regulated by $\mathrm{Mn}$ toxicity. Plant $\mathrm{ABC}$ transporters constitute a large superfamily and are implicated in the transport of a variety of substrates, including hormones, secondary metabolites and heavy metal ions [56]. It has been demonstrated that the transcripts of OsABCG43, belonging to the rice $\mathrm{ABC}$ transporter, is up-regulated by $\mathrm{Cd}$ treatment; overexpression of OsABCG43 confers $\mathrm{Cd}$ tolerance in the Cd-sensitive yeast mutant $y c f 1 a c r 3$, suggesting that the role of OsABCG43 in sequestration of Cd into subcellular organelles (e.g., vacuoles) [57]. OsALS1, encoding a halfsize $A B C$ transporter in rice, is found to be localized at the tonoplast and is required for $\mathrm{Al}$ detoxification through sequestration of $\mathrm{Al}$ into the vacuoles [58]. A similar result has been reported in Arabidopsis that AtALS1 participates in $\mathrm{Al}$ sequestration [59]. Furthermore, studies on cyanobacterium (Synechocystis) also suggest the potential role of $\mathrm{ABC}$ transporter in $\mathrm{Mn}$ transport [60]. Therefore, genes encoding $A B C$ transporters are probably involved in stylo leaves defense against Mn toxicity.

Furthermore, genes encoding cation $/ \mathrm{H}^{+}$exchangers were found to be up-regulated by $\mathrm{Mn}$ toxicity in this study (Additional file 7: Table S6). The cation $/ \mathrm{H}^{+}$exchanger plays important roles in the vacuolar accumulation of metals, such as $\mathrm{Mn}$. For example, the cation $/ \mathrm{H}^{+}$ exchanger in Arabidopsis, AtCAX2, is involved in conferring tolerance to $\mathrm{Mn}$ toxicity when it is heterologously expressed in a Mn-sensitive yeast mutant pmc1vcxlcnb or in tobacco (Nicotiana tabacum) via sequestration of $\mathrm{Mn}$ into vacuoles [61]. Similar functions have been assigned to AtCAX4 and AtCAX5, which localize to the vacuolar membrane $[62,63]$. In addition, one gene encoding homologs to aquaporin protein, aquaporin TIP1-3-like, was also up-regulated by $\mathrm{Mn}$ toxicity in stylo leaves (Additional file 7: Table S6). Genes belonging to the aquaporin protein family are reported to be involved in plants response to metal stresses. For example, two genes encoding tonoplastintrinsic protein (TIP) are regulated by $\mathrm{Al}$ toxicity in buckwheat (Fagopyrum esculentum) leaves [64]. It has been demonstrated that HmVALT, belonging to the tonoplast-intrinsic protein in $\mathrm{Al}$ hyperaccumulating hydrangea (Hydrangea macrophylla), is a tonoplastlocalized $\mathrm{Al}$ transporter that involves in vacuolar $\mathrm{Al}$ transport; overexpression of HmVALT confers $\mathrm{Al}$ tolerance in Arabidopsis [65]. There results suggest the potential roles of this gene in vacuolar Mn transport.

In addition, a group of genes belonging to transporters for various substrates, including phosphate, potassium and copper, were found to be differentially regulated by Mn in stylo leaves (Additional file 7: Table S6). The balance between the accumulation of $\mathrm{Mn}$ and other abundant mineral elements is thought to be important for regulating $\mathrm{Mn}$ homeostasis in plants [33]. Thus, these DEGs related to transporters responsible for Mn translocation, distribution and sequestration are regarded to be critical for intracellular Mn detoxification in stylo, and their functions warrant further investigation.

\section{Conclusion}

In conclusion, this study showed that stylo growth was inhibited by high Mn due to oxidative stress. Consistently, transcriptome analysis showed that a set of DEGs involved in regulating ROS scavenging and defense responses might contribute to stylo's response to Mn toxicity. Furthermore, the identified DEGs associated with secondary metabolic pathways suggested that fine-tuned regulation of secondary metabolism might represent an adaptive strategy of stylo to cope with Mn toxicity. In addition, activation of various transcription factors may help stylo to tolerate $\mathrm{Mn}$ toxicity through transcriptional regulation. Taken together, this study not only reveals new insights into the molecular mechanisms underlying stylo's response to Mn toxicity but also provides candidate genes that may be useful in the development of 
crop varieties with $\mathrm{Mn}$ adaptability through genetic engineering.

\section{Methods}

\section{Plant growth and treatments}

The stylo (Stylosanthes guianensis) genotype 'TF303' used in this study was provided by the Tropical Pasture Research Center, Institute of Tropical Crop Genetic Resources (TCGRI), Chinese Academy of Tropical Agriculture Sciences (CATAS), Hainan, China (voucher specimen deposited in the National Tropical Forage Germplasm Genebank, TCGRI, CATAS). The plant material was authenticated by Guodao Liu, TCGRI, CATA S. All experimental procedures were performed at the TCGRI, CATAS, Hainan, China $\left(19^{\circ} 30^{\prime} \mathrm{N}, 109^{\circ} 30^{\prime} \mathrm{E}\right)$. After seed germination, stylo seedlings were transferred to a modified Hoagland nutrient solution ( $\mathrm{pH}$ 5.8) containing $2500 \mu \mathrm{M} \mathrm{KNO}_{3}, 2500 \mu \mathrm{M} \mathrm{Ca}\left(\mathrm{NO}_{3}\right)_{2}, 400 \mu \mathrm{M}$ $\mathrm{NH}_{4} \mathrm{NO}_{3}, 250 \mu \mathrm{M} \mathrm{KH}_{2} \mathrm{PO}_{4}, 500 \mu \mathrm{M} \mathrm{MgSO}_{4}, 250 \mu \mathrm{M}$ $\mathrm{K}_{2} \mathrm{SO}_{4}, 5 \mu \mathrm{M} \mathrm{MnSO}_{4}, 0.5 \mu \mathrm{M} \mathrm{ZnSO}, 1.5 \mu \mathrm{M} \mathrm{CuSO}_{4}$, $0.09 \mu \mathrm{M}\left(\mathrm{NH}_{4}\right)_{6} \mathrm{Mo}_{7} \mathrm{O}_{24}, 23 \mu \mathrm{M} \mathrm{NaB} \mathrm{O}_{7}$ and $80 \mu \mathrm{M}$ FeNa-EDTA [26]. After $30 \mathrm{~d}$ of normal growth, stylo seedlings were transplanted into fresh nutrient solution supplied with 5, 100, 200, 400 and $800 \mu \mathrm{M} \mathrm{MnSO}_{4}$ (pH 5.0). The background $\mathrm{Mn}$ level in the nutrient solution is $5 \mu \mathrm{M}$ and thus used as the control [26]. After $10 \mathrm{~d}$ of $\mathrm{Mn}$ treatments, shoots and roots were harvested for further study. An individual hydroponic box containing four stylo seedlings served as one biological replicate. All treatments included three biological replicates.

\section{Analysis of chlorophyll concentrations}

To analyze chlorophyll concentrations, approximately $0.05 \mathrm{~g}$ leaf sample was incubated in $10 \mathrm{~mL}$ of $80 \%(\mathrm{v} / \mathrm{v})$ acetone for $6 \mathrm{~h}$. The chlorophyll concentration was spectrophotometrically detected at 440, 645 and $663 \mathrm{~nm}$ using a UV-2010 spectrophotometer (Hitachi, Japan) and determined as previously described [26].

\section{Determination of $\mathrm{Mn}$ concentrations}

To measure $\mathrm{Mn}$ concentrations, approximately $0.07 \mathrm{~g}$ dry shoot and root samples were transferred to a muffle furnace and burned at $600{ }^{\circ} \mathrm{C}$ for $10 \mathrm{~h}$. Then, the sample was adequately extracted in $7 \mathrm{~mL}$ of $100 \mathrm{mM} \mathrm{HCl}$. Mn concentrations in each sample were detected using atomic absorption spectroscopy [11].

\section{Detection of $\mathrm{O}_{2}{ }^{-}$and MDA levels}

$\mathrm{O}_{2}{ }^{-}$levels in stylo leaves were detected using the histochemical method [66]. Leaves subjected to different $\mathrm{Mn}$ treatments were incubated in $0.25 \mathrm{mM}$ NBT solution for $12 \mathrm{~h}$. Samples were then decolorized in boiling ethanol for $6 \mathrm{~h} . \mathrm{O}_{2}{ }^{-}$levels were assessed in leaves based on the intensity of the blue insoluble formazan.
For MDA analysis, approximately $0.1 \mathrm{~g}$ samples were extracted in $1 \mathrm{~mL}$ of $10 \%$ trichloracetic acid (TCA). Homogenates were centrifuged at $12,000 \times g$ for $10 \mathrm{~min}$. The supernatants were collected, and $1 \mathrm{~mL}$ supernatant was added to $1 \mathrm{~mL}$ of $0.5 \%$ thiobarbituric acid (TBA). The mixture was then incubated at $100^{\circ} \mathrm{C}$ for $20 \mathrm{~min}$. Then, homogenates were centrifuged at $12,000 \times g$ for $10 \mathrm{~min}$. The MDA concentration was detected as previously described [67].

\section{Analysis of electrolyte leakage and $\mathrm{Fv} / \mathrm{Fm}$}

Stylo leaves treated with various $\mathrm{Mn}$ concentrations were separately immersed in $10 \mathrm{~mL}$ of deionized water in a glass test tube overnight at room temperature. The initial conductivity (IC) of the solution was detected using a conductimeter (INESA Scientific Instrument Co., Ltd., Shanghai, China). Total conductivity (TC) of the solution was detected after boiling for $15 \mathrm{~min}$. Relative electrolyte leakage was expressed as the percentage of the initial conductivity (IC) to the total conductivity (TC). $F \mathrm{v} / F \mathrm{~m}$ values of stylo leaves were measured using a pulse-modulated fluorometer Model FMS-2 (Hansatech Instruments Ltd., UK) according to the manufacturer's instructions.

\section{Analysis of enzyme activity}

To determine POD activity, approximately $0.1 \mathrm{~g}$ leaf samples from different $\mathrm{Mn}$ treatments were extracted in $2 \mathrm{~mL}$ of $50 \mathrm{mM}$ phosphate buffer $(\mathrm{pH} 7.8)$ at $4{ }^{\circ} \mathrm{C}$. The extracts were centrifuged at $12,000 \times g$ for $15 \mathrm{~min}$ at $4{ }^{\circ} \mathrm{C}$, and the supernatants were recovered for POD assay [66]. APX was extracted by grinding $0.1 \mathrm{~g}$ leaves in $2 \mathrm{~mL}$ of $50 \mathrm{mM}$ phosphate buffer ( $\mathrm{pH}$ 7.0) supplied with $1 \mathrm{mM}$ AsA and $1 \mathrm{mM}$ ethylenediaminetetraacetic acid (EDTA) at $4{ }^{\circ} \mathrm{C}$. After centrifugation, the supernatants were collected for APX activity assays [66].

To detect PPO activity, approximately $0.1 \mathrm{~g}$ leaf samples were extracted in $1 \mathrm{~mL}$ of extraction buffer obtained from commercial assay kits (Solarbio Science and Technology Co., Ltd., Beijing, China) at $4{ }^{\circ} \mathrm{C}$. The extracts were centrifuged at $12,000 \times g$ for $15 \mathrm{~min}$ at $4{ }^{\circ} \mathrm{C}$, and supernatants were collected for PPO activity assessment at $410 \mathrm{~nm}$. PPO activity was calculated according to the manufacturer's protocol. To analyze PAL activity, $0.1 \mathrm{~g}$ leaf samples were extracted in $0.9 \mathrm{~mL}$ of extraction buffer obtained from commercial assay kits (Nanjing Jiancheng Bioengineering Institute, Jiangsu, China) at $4{ }^{\circ} \mathrm{C}$. After centrifugation, the supernatants were used to determine PAL activity at $290 \mathrm{~nm}$ according to the protocol.

\section{Transcriptome analysis of stylo leaves}

RNA sequencing was performed by Annoroad Gene Technology Co., Ltd. (Beijing, China). Total RNA of 
stylo leaves subjected to control $(5 \mu \mathrm{M})$ and $\mathrm{Mn}$ toxicity $(400 \mu \mathrm{M})$ treatments was isolated using TRIzol reagent (Invitrogen, Carlsbad, CA, USA). RNA integrity and purity were analyzed using an Agilent 2100 RNA Nano 6000 Assay Kit (Agilent Technologies, Palo Alto, CA, USA). Sequencing libraries were generated using the NEBNext Ultra Directional RNA Library Prep kit (NEB, Beverly, MA, USA). The cDNA libraries of the three biological replicates were obtained using an Illumina Hiseq 4000 platform (Illumina, San Diego, CA, USA). PE150 was used as the sequencing program.

Raw image data were transformed to raw reads using the Consensus Assessment of Sequence and Variation (CASAVA, v.1.8.2) base recognition program. The raw reads were stored in FASTQ files. High-quality clean reads were obtained by filtering out adaptor sequences and low-quality reads. The obtained clean reads were further assembled into unigenes using Trinity software (version 2.4.0) [68]. The clean reads were mapped back to the assembled contigs through Bowtie2 v.2.2.3 software [69]. For annotation, all unigene sequences were aligned by BLAST search (E-value $<1 \mathrm{e}-5)$ against the NCBI non-redundant protein sequences $(\mathrm{Nr})$, NCBI non-redundant nucleotide sequences $(\mathrm{Nt})$, Universal Protein (UniProt), Gene Ontology (GO), the Clusters of Orthologous Groups of protein database (COG), the Functional Annotation (eggNOG), the KEGG database and the Protein Family (Pfam).

The transcript abundance of each gene in each sample was calculated and represented by the reads per kilobase million mapped reads (RPKM) value using RNA-seq data with expectation maximization (RSEM) [70]. DESeq2 was used to calculate the differences in the expression abundance between 5 and $400 \mu \mathrm{M}$ Mn treatments [71]. Genes with $q<0.05$ and $\mid \log _{2}$ (fold change) $\mid$ $\geq 1$ were considered DEGs. Subsequently, DEGs were extracted for GO and KEGG enrichment analysis [72, 73]. Protein-protein interaction network analysis for the identified DEGs was performed using STRING (version 11.0) (https://string-db.org/). The interaction networks were constructed using Cytoscape (version 3.8.0) (https://github.com/cytoscape/cytoscape) with default settings. Nodes and edges indicate genes and interactions, respectively. The sequencing data were deposited in the National Center for Biotechnology Information (NCBI) Gene Expression Omnibus under GEO series number GSE147431.

\section{Quantitative real-time PCR (qRT-PCR) analysis}

Total RNA from leaves was extracted using the TRIzol reagent (Invitrogen, USA) according to the manual. The first cDNA strand was synthesized from $2 \mu \mathrm{g}$ of DNase I-treated RNA using oligo d(T), dNTPs, RNase inhibitor and reverse transcriptase in the HiScript III cDNA synthesis kit (Vazyme, China) according to the protocol. qRT-PCR analysis was performed in a $20 \mu \mathrm{L}$ volume containing $2 \mu \mathrm{L}$ 1:50 diluted cDNA, $0.2 \mu \mathrm{M}$ gene primers, $6.4 \mu \mathrm{L} \mathrm{ddH}_{2} \mathrm{O}$ and $10 \mu \mathrm{L}$ SYBR Green Master mix (Vazyme, China). The reaction was performed on a QuantStudio $^{\text {tw }} 6$ Flex Real-Time System (Thermo Fisher Scientific, Waltham, MA, USA). qRT-PCR analysis conditions were as follows: $95^{\circ} \mathrm{C}$ for $1 \mathrm{~min}, 40$ cycles of $95^{\circ} \mathrm{C}$ for $15 \mathrm{~s}, 58^{\circ} \mathrm{C}$ for $15 \mathrm{~s}$ and $72{ }^{\circ} \mathrm{C}$ for $30 \mathrm{~s}$. qRT-PCR primers of genes are listed in Additional file 8: Table S7. The housekeeping gene SgEF-1a (Accession No. JX164254) was used as an endogenous control to calculate the relative gene expression as the ratio of the transcript of the candidate gene to that of SgEF-1a [26]. Gene expression analysis included three biological replicates.

\section{Determination of secondary metabolite concentrations}

The concentrations of secondary metabolites, including total phenols, flavonoids, anthocyanins and tannins, in stylo leaves exposed to various Mn treatments were analyzed using commercial assay kits (Nanjing Jiancheng Bioengineering Co., Ltd., Jiangsu, China). To detect total phenols, flavonoids and anthocyanins, $0.1 \mathrm{~g}$ dry leaf samples were extracted and measured as previously described [66]. For tannin assays, approximately $0.1 \mathrm{~g}$ fresh leaf samples were extracted in $1 \mathrm{~mL}$ of $\mathrm{ddH}_{2} \mathrm{O}$. The concentration of tannins was detected according to the manufacturer's protocol.

\section{Statistical analysis}

Microsoft Excel 2003 (Microsoft Company, USA) was used in the data analysis. One-way analysis of variance (ANOVA) was performed using SPSS software, version 13.0 (SPSS Institute, Chicago, USA).

\section{Supplementary Information}

The online version contains supplementary material available at https://doi. org/10.1186/s12864-020-07279-2.

Additional file 1: Figure S1. Effects of different Mn treatments on relative electrolyte leakage, Fv/Fm, plant height and total protein content.

Additional file 2: Table S1. Summary of stylo leave transcriptomes in control $(5 \mu \mathrm{M})$ and $\mathrm{Mn}$ toxicity $(400 \mu \mathrm{M})$ libraries.

Additional file 3: Table S2. Information of DEGs identified in stylo leaves subjected to control $(5 \mu \mathrm{M})$ and $\mathrm{Mn}$ toxicity $(400 \mu \mathrm{M})$ treatments.

Additional file 4: Table S3. DEGs involved in secondary metabolism. Additional file 5: Table S4. Transcription factors responding to $\mathrm{Mn}$ toxicity.

Additional file 6: Table S5. DEGs involved in defense responses.

Additional file 7: Table S6. DEGs related to transporters.

Additional file 8: Table S7. Primers used for qRT-PCR analysis. 
CHI: Chalcone isomerase; CHS: Chalcone synthase; COMT: Caffeoyl-CoA Omethyltransferase; CSE: Caffeoylshikimate esterase; DEGs: Differentially expressed genes; F3'5'H: Flavonoid 3,5-hydroxylase; F6H: Feruloyl-CoA 6hydroxylase; FLS: Flavonol synthase; GLU: Beta-glucosidase; GO: Gene Ontology; GST: Glutathione S-transferase; HI4OMT: 2,7,4-

Trihydroxyisoflavanone 4-O-methyltransferase/isoflavone 4-O-

methyltransferase; HIDH: 2-Hydroxyisoflavanone dehydratase; $12 \mathrm{H}$ : Isoflavone 2-hydroxylase; 17OMT: sofilavone-7-O-methyltransferase; KEGG: Kyoto Encyclopedia of Genes and Genomes; MDA: Malondialdehyde; NBT: Nitroblue tetrazolium chloride; PAL: Phenylalanine ammonia-lyase; POD: Peroxidase; PPO: Polyphenol oxidase; qRT-PCR: Quantitative real-time polymerase chain reaction; RNA-seq: RNA sequencing; ROS: Reactive oxygen species; SOD: Superoxide dismutase; SPL19: Serine carboxypeptidase-like 19, TFs: Transcription factors; VR: Vestitone reductase

\section{Acknowledgements}

We thank Mr. Chun Liu for providing critical comments about this work. We sincerely thank American Journal Experts (https://www.aje.com/) for critical review on this manuscript.

\section{Authors' contributions}

$\mathrm{ZC}$ and $\mathrm{LL}$ conceived and designed the research. $\mathrm{YJ}, \mathrm{XL}$, $J \mathrm{~L}$ and $\mathrm{RD}$ performed the physiological experiments. YJ, XL and QL analyzed the RNASeq data. XH and PL carried out genes expression analysis. GL provided and prepared the plant material as well as analyzed and interpreted the results for this work. ZC, YJ and XL wrote the manuscript. GL, LL and ZC substantially revised the manuscript. All authors read and approved the final manuscript.

\section{Funding}

This work is supported by the National Natural Science Foundation of China (31801951, 31672483, 31861143013), the Central Public-interest Scientific Institution Basal Research Fund for CATAS (1630032020004, 1630032019002, 1630032018004), the Modern Agro-industry Technology Research System (CARS-34), and the Integrated Demonstration of Key Techniques for the Industrial Development of Featured Crops in Rocky Desertification Areas of Yunnan-Guangxi-Guizhou Provinces (SMH2019-2021). The funding bodies had no roles in the design of the study and collection, analysis, and interpretation of data and in writing the manuscript.

\section{Availability of data and materials}

The datasets for this study can be found in the NCBI Gene Expression Omnibus under GEO series number of GSE147431.

\section{Ethics approval and consent to participate}

This study did not involve field experiment. The stylo plant used in this study was provided by the Tropical Pasture Research Center, Institute of Tropical Crop Genetic Resources (TCGRI), Chinese Academy of Tropical Agriculture Sciences (CATAS), Hainan, China. All experimental procedures concerning on the plant were conducted in accordance with the institutional and national guidelines of China. This research did not include experiments concerning on human participants or animals.

\section{Consent for publication}

Not applicable.

\section{Competing interests}

The authors declare that they have no competing interests.

\section{Author details}

'Institute of Tropical Crop Genetic Resources, Chinese Academy of Tropical Agricultural Sciences, Haikou 571101, China. ${ }^{2}$ Hainan Key Laboratory for Sustainable Utilization of Tropical Bioresources, College of Tropical Crops, Hainan University, Haikou 570110, China. ${ }^{3}$ College of Biology and Pharmacy, Yulin Normal University, Yulin 537000, China.
Received: 5 May 2020 Accepted: 24 November 2020

Published online: 03 December 2020

\section{References}

1. Millaleo R, Reyes-Díaz M, Ivanov AG, Mora ML, Alberdi M. Manganese as essential and toxic element for plants: transport, accumulation and resistance mechanism. J Soil Sci Plant Nutr. 2010;10:470-81.

2. Lidon FC, Barreiro MG, Ramalho JC. Manganese accumulation in rice: implications for photosynthetic functioning. J Plant Physiol. 2004;161:123544.

3. Shao JF, Yamaji N, Shen RF, Ma JF. The key to Mn homeostasis in plants: regulation of Mn transporters. Trends Plant Sci. 2017;22:215-24.

4. Geszvain K, Butterfield C, Davis RE, Madison AS, Lee SW, Parker DL, et al. The molecular biogeochemistry of manganese (II) oxidation. Biochem Soc Trans. 2012;40:1244-8.

5. Sparrow LA, Uren NC. Manganese oxidation and reduction in soils: effects of temperature, water potential, $\mathrm{pH}$ and their interactions. Soil Res. 2014;52: 483-94.

6. Watmough SA, Eimers MC, Dillon PJ. Manganese cycling in Central Ontario forests: response to soil acidification. Appl Geochem. 2007;22:1241-7.

7. Hue NV, Mai Y. Manganese toxicity in watermelon as affected by lime and compost amended to a Hawaiian acid Oxisol. HortScience. 2002;37:656-61.

8. Fernando DR, Lynch JP. Manganese phytotoxicity: new light on an old problem. Ann Bot. 2015;116:313-9.

9. Li JF, Jia YD, Dong RS, Huang R, Liu PD, Li XY, et al. Advances in the mechanisms of plant tolerance to manganese toxicity. Int J Mol Sci. 2019;20: 5096.

10. Ribera-Fonseca A, Inostroza-Blancheteau C, Cartes P, Rengel Z, Mora ML. Early induction of $\mathrm{Fe}-\mathrm{SOD}$ gene expression is involved in tolerance to $\mathrm{Mn}$ toxicity in perennial ryegrass. Plant Physiol Biochem. 2013;73:77-82.

11. Liu P, Huang R, Hu X, Jia Y, Li J, Luo J, et al. Physiological responses and proteomic changes reveal insights into Stylosanthes response to manganese toxicity. BMC Plant Biol. 2019;19:212.

12. Fecht-Christoffers $M M$, Führs $\mathrm{H}$, Braun $\mathrm{HP}$, Horst WJ. The role of $\mathrm{H}_{2} \mathrm{O}_{2}$ producing and $\mathrm{H}_{2} \mathrm{O}_{2}$-consuming peroxidases in the leaf apoplast of Vigna unguiculata L. in manganese tolerance. Plant Physiol. 2006;140:1451-63.

13. Lei Y, Korpelainen H, Li C. Physiological and biochemical responses to high $\mathrm{Mn}$ concentrations in two contrasting Populus cathayana populations. Chemosphere. 2007;68:686-94

14. Pittman JK. Managing the manganese: molecular mechanisms of manganese transport and homeostasis. New Phytol. 2005:167:733-42.

15. Socha AL, Guerinot ML. Mn-euvering manganese: the role of transporter gene family members in manganese uptake and mobilization in plants. Front Plant Sci. 2014;5:106.

16. Yamaji N, Sasaki A, Xia JX, Yokosho K, Ma JF. A node-based switch for preferential distribution of manganese in rice. Nat Commun. 2013;4: 2442.

17. Delhaize E, Kataoka T, Hebb DM, White RG, Ryan PR. Genes encoding proteins of the cation diffusion facilitator family that confer manganese tolerance. Plant Cell. 2003;15:1131-42.

18. Chen Z, Fujii Y, Yamaji N, Masuda S, Takemoto Y, Kamiya T, et al. Mn tolerance in rice is mediated by MTP8.1, a member of the cation diffusion facilitator family. J Exp Bot. 2013;64:4375-87.

19. Takemoto Y, Tsunemitsu Y, Fujii KM, Mitani UN, Yamaji N, Ma JF, et al. The tonoplast-localized transporter MTP8.2 contributes to manganese detoxification in the shoots and roots of Oryza sativa L. Plant Cell Physiol. 2017;58:1573-82.

20. Eroglu S, Meier B, Wirén NV, Peiter E. The vacuolar manganese transporter MTP8 determines tolerance to iron deficiency-induced chlorosis in Arabidopsis. Plant Physiol. 2016;170:1030-45.

21. Migocka M, Papierniak A, Dziubińska EM, Poździk P, Posyniak E, Garbiec A, et al. Cucumber metal transport protein MTP8 confers increased tolerance to manganese when expressed in yeast and Arabidopsis thaliana. J Exp Bot. 2014;65:5367-84.

22. Li Q, Li Y, Wu X, Zhou L, Zhu X, Fang W. Metal transport protein 8 in Camellia sinensis confers superior manganese tolerance when expressed in yeast and Arabidopsis thaliana. Sci Rep. 2017;7:39915.

23. Schultze-Kraft R, Rao IM, Peters M, Clements RJ, Bai C, Liu GD. Tropical forage legumes for environmental benefits: an overview. Trop Grassl Forrajes. 2018;6:1-14. 
24. Guo PF, Liu PD, Lei J, Chen CH, Qiu H, Liu GD, et al. Improvement of plant regeneration and Agrobacterium-mediated genetic transformation of Stylosanthes guianensis. Trop Grassl Forrajes. 2019;7:480-92.

25. Andrew CS, Hegarty MP. Comparative responses to manganese excess of eight tropical and four temperate pasture legume species. Aust J Agvic Res. 1969;20:687-96.

26. Chen ZJ, Sun LL, Liu PD, Liu GD, Tian J, Liao H. Malate synthesis and secretion mediated by a manganese-enhanced malate dehydrogenase confers superior manganese tolerance in Stylosanthes guianensis. Plant Physiol. 2015;167:176-88.

27. Nagajyoti PC, Lee KD, Sreekanth TVM. Heavy metals, occurrence andtoxicity for plants: a review. Environ Chem Lett. 2010;8:199-216.

28. Lucchini R, Placidi D, Cagna G, Fedrighi C, Oppini M, Peli M, et al. Manganese and developmental neurotoxicity. Adv Neurobiol. 2017;18: 13-34.

29. Zhang P, Ding Z, Zhong Z, Tong H. Transcriptomic analysis for Indica and Japonica rice varieties under aluminum toxicity. Int J Mol Sci. 2019; 20:997.

30. Jiang W, Wu Z, Wang T, Mantri N, Huang H, Li H, et al. Physiological and transcriptomic analyses of cadmium stress response in Dendrobium officinale seedling. Plant Physiol Biochem. 2020;148:152-65.

31. Wang YM, Yang Q, Xu H, Liu YJ, Yang HL. Physiological and transcriptomic analysis provide novel insight into cobalt stress responses in willow. Sci Rep. 2020;10:2308.

32. Rosas A, Rengel Z, Mora ML. Manganese supply and pH influence growth, carboxylate exudation and peroxidase activity of ryegrass and white clover. J Plant Nutr. 2007;30:253-70.

33. Sheng H, Zeng J, Yan F, Wang X, Wang Y, Kang H. Effect of exogenous salicylic acid on manganese toxicity, mineral nutrients translocation and antioxidative system in polish wheat (Triticum polonicum L.). Acta Physiol Plant. 2015;37:32.

34. Zhou CP, Qi YP, You X, Yang LT, Guo P, Ye X, et al. Leaf CDNA-AFLP analysis of two citrus species differing in manganese tolerance in response to longterm manganese-toxicity. BMC Genomics. 2013;14:621.

35. Kumar S, Asif MH, Chakrabarty D, Tripathi RD, Dubey RS, Trivedi PK. Expression of a rice lambda class of glutathione S-transferase, OSGSTL2, in Arabidopsis provides tolerance to heavy metal and other abiotic stresses. J Hazard Mater. 2013;248-249:228-37.

36. Dmitriev AA, Krasnov GS, Rozhmina TA, Kishlyan NV, Zyablitsin AV, Sadritdinova AF, et al. Glutathione S-transferases and UDPglycosyltransferases are involved in response to aluminum stress in flax. Front Plant Sci. 2016;7:1920.

37. Mészáros P, Rybanský L, Spieß N, Socha P, Kuna R, Libantová J, et al. Plant chitinase responses to different metal-type stresses reveal specificity. Plant Cell Rep. 2014;33:1789-99.

38. Liu Y, Li D, Song Q, Zhang T, Li D, Yang X. The maize late embryogenesis abundant protein $\mathrm{ZmDHN13}$ positively regulates copper tolerance in transgenic yeast and tobacco. Crop J. 2019;7:403-10.

39. Cochrane FC, Davin LB, Lewis NG. The Arabidopsis phenylalanine ammonialyase gene family: kinetic characterization of the four PAL isoforms. Phytochemistry. 2004;65:1557-64.

40. Sharma A, Shahzad B, Rehman A, Bhardwaj R, Landi M, Zheng B. Response of phenylpropanoid pathway and the role of polyphenols in plants under abiotic stress. Molecules. 2019;24:2452.

41. Pawlak-Sprada S, Arasimowicz-Jelonek M, Podgórska M, Deckert J. Activation of phenylpropanoid pathway in legume plants exposed to heavy metals. Part I. effects of cadmium and lead on phenylalanine ammonia-lyase gene expression, enzyme activity and lignin content. Acta Biochim Pol. 2011;58: 211-6.

42. Bali S, Jamwal VL, Kohli SK, Kaur P, Tejpal R, Bhalla V, et al. Jasmonic acid application triggers detoxification of lead $(\mathrm{Pb})$ toxicity in tomato through the modifications of secondary metabolites and gene expression. Chemosphere. 2019;235:734-48.

43. Falcone-Ferreyra ML, Rius SP, Emiliani J, Pourcel L, Feller A, Morohashi K, et al. Cloning and characterization of a UV-B-inducible maize flavonol synthase. Plant J. 2010;62:77-91.

44. Dao TTH, Linthorst HJM, Verpoorte R. Chalcone synthase and its functions in plant resistance. Phytochem Rev. 2011;10:397-412.

45. Rivera-Becerril F, Metwally A, Martin-Laurent F, Tuinen DV, Dietz KJ, Gianinazzi S, et al. Molecular responses to cadmium in roots of Pisum sativum L. Water Air Soil Poll. 2005;168:171-86.
46. Dixon RA, Steele CL. Flavonoids and isoflavonoids-a gold mine for metabolic engineering. Trends Plant Sci. 1999;4:394-400.

47. Pawlak-Sprada S, Stobiecki M, Deckert J. Activation of phenylpropanoid pathway in legume plants exposed to heavy metals. Part II. Profiling of isoflavonoids and their glycoconjugates induced in roots of lupine (Lupinus luteus) seedlings treated with cadmium and lead. Acta Biochim Pol. 2011;58: 217-23.

48. Sawaki Y, luchi S, Kobayashi Y, Kobayashi Y, Ikka T, Sakurai N, et al. STOP1 regulates multiple genes that protect Arabidopsis from proton and aluminum toxicities. Plant Physiol. 2009;150:281-94.

49. Kobayashi Y, Ohyama Y, Kobayashi Y, Ito H, luchi S, Fujita M, et al. STOP2 activates transcription of several genes for $\mathrm{Al}$ and low $\mathrm{pH}$ tolerance that are regulated by STOP1 in Arabidopsis. Mol Plant. 2014;7:311-22.

50. Fan W, Lou HQ, Gong YL, Liu MY, Cao MJ, Liu Y, et al. Characterization of an inducible $\mathrm{C}_{2} \mathrm{H}_{2}$-type zinc finger transcription factor VuSTOP1 in rice bean (Vigna umbellata) reveals differential regulation between low $\mathrm{pH}$ and aluminum tolerance mechanisms. New Phytol. 2015;208:456-68.

51. Wu W, Lin Y, Chen Q, Peng W, Peng J, Tian J, et al. Functional conservation and divergence of soybean GmSTOP1 members in proton and aluminum tolerance. Front Plant Sci. 2018;9:570.

52. Ding ZJ, Yan JY, Xu XY, Li GX, Zheng SJ. WRKY46 functions as a transcriptional repressor of ALMT1, regulating aluminum induced malate secretion in Arabidopsis. Plant J. 2013;76:825-35.

53. Dubos C, Stracke R, Grotewold E, Weisshaar B, Martin C, Lepiniec L. MYB transcription factors in Arabidopsis. Trends Plant Sci. 2010;15:573-81.

54. Zhang P, Wang R, Ju Q, Li W, Tran LS, Xu J. The R2R3-MYB transcription factor MYB49 regulates cadmium accumulation. Plant Physiol. 2019;180:529_ 42.

55. Wang FZ, Chen MX, Yu LU, Xie LJ, Yuan LB, Qi H, et al. OsARM1, an R2R3 $M Y B$ transcription factor, is involved in regulation of the response to arsenic stress in rice. Front Plant Sci. 2017:8:1868.

56. Jasinski M. The ATP-binding cassette transporters: structure, function, and gene family comparison between rice and Arabidopsis. Plant Physiol. 2003; 131:1169-77.

57. Oda K, Otani M, Uraguchi S, Akihiro T, Fujiwara T. Rice ABCG43 is cd inducible and confers cd tolerance on yeast. Biosci Biotechnol Biochem. 2011;75:1211-3.

58. Huang CF, Yamaji N, Chen Z, Ma JF. A tonoplast-localized half-size ABC transporter is required for internal detoxification of aluminum in rice. Plant J. 2012;69:857-67.

59. Larsen PB, Cancel J, Rounds M, Ochoa V. Arabidopsis ALS1 encodes a root tip and stele localized half type $A B C$ transporter required for root growth in an aluminum toxic environment. Planta. 2007:225:1447-58.

60. Bartsevich $\mathrm{V}$, Pakrasi HB. Manganese transport in the cyanobacterium Synechocystis sp PCC 6803. J Biol Chem. 1996;271:26057-61.

61. Hirschi KD, Korenkov VD, Wilganowski NL, Wagner GJ. Expression of Arabidopsis CAX2 in tobacco. Altered metal accumulation and increased manganese tolerance. Plant Physiol. 2000;124:125-33.

62. Cheng NH, Pittman JK, Shigaki T, Hirschi KD. Characterization of CAX4, an Arabidopsis $\mathrm{H}^{+}$/cation antiporter. Plant Physiol. 2002;128:1245-54.

63. Edmond C, Shigaki T, Ewert S, Nelson MD, Connorton JM, Chalova V, et al. Comparative analysis of CAX2-like cation transporters indicates functional and regulatory diversity. Biochem J. 2009;418:145-54.

64. Chen WW, Xu JM, Jin JF, Lou HQ, Fan W, Yang JL. Genome-wide transcriptome analysis reveals conserved and distinct molecular mechanisms of Al resistance in buckwheat (Fagopyrum esculentum Moench) leaves. Int J Mol Sci. 2017;18:1859.

65. Negishi T, Oshima K, Hattori M, Kana M, Mano S, Nishimura M, et al. Tonoplast-and plasma membrane-localized aquaporin-family transporters in blue hydrangea sepals of aluminum hyperaccumulating plant. PLoS One. 2012;7:e43189.

66. Wang H, Chen ZJ, Liu GD, Bai CJ, Qiu H, Jia YX, et al. Alterations of growth, antioxidant system and gene expression in Stylosanthes guianensis during Colletotrichum gloeosporioides infection. Plant Physiol Biochem. 2017;118: 256-66.

67. Guo Z, Huang M, Lu S, Zhao Y, Zhong Q. Differential response to paraquat induced oxidative stress in two rice cultivars on antioxidants and chlorophyll a fluorescence. Acta Physiol Plant. 2007;29:39-46.

68. Grabherr MG, Haas BJ, Yassour M, Levin JZ, Thompson DA, Amit I, et al. Fulllength transcriptome assembly from RNA-Seq data without a reference genome. Nat Biotechnol. 2011;29:644-52. 
69. Langmead B, Trapnell C, Pop M, Salzberg SL. Ultrafast and memory-efficient alignment of short DNA sequences to the human genome. Genome Biol. 2009;10:25-34

70. Li B, Dewey CN. RSEM: accurate transcript quantification from RNA-Seq data with or without a reference genome. BMC Bioinform. 2011;12:323.

71. Love Ml, Huber W, Anders S. Moderated estimation of fold change and dispersion for RNA-seq data with DESeq2. Genome Biol. 2014;15:550.

72. Kanehisa M, Goto S. KEGG: Kyoto encyclopedia of genes and genomes. Nucleic Acids Res. 2000;28:27-30.

73. Zhao N, Li W, Bai S, Guo W, Yuan G, Wang F, et al. Transcriptome profiling to identify genes involved in mesosulfuron-methyl resistance in Alopecurus aequalis. Front Plant Sci. 2017;8:1391.

\section{Publisher's Note}

Springer Nature remains neutral with regard to jurisdictional claims in published maps and institutional affiliations.

- fast, convenient online submission

- thorough peer review by experienced researchers in your field

- rapid publication on acceptance

- support for research data, including large and complex data types

- gold Open Access which fosters wider collaboration and increased citations

- maximum visibility for your research: over $100 \mathrm{M}$ website views per year

At BMC, research is always in progress.

Learn more biomedcentral.com/submissions 